\author{
Defense Threat Reduction Agency \\ 8725 John J. Kingman Road, MS-6201 \\ Fort Belvoir, VA 22060-6201
}

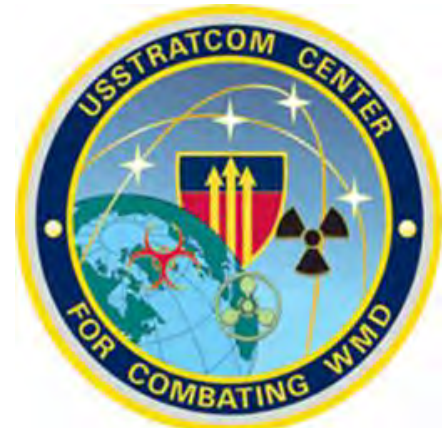

DTRA-TR-15-070

\title{
An Overview of the Technical Basis of HENRE 2.0 Models
}

DISTRIBUTION A. Approved for public release: distribution is unlimited.

August 2015 


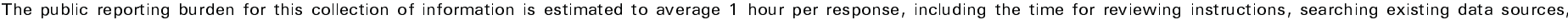

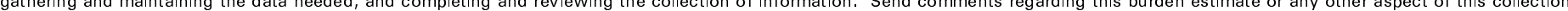

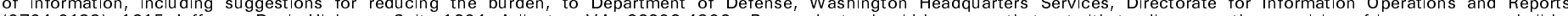

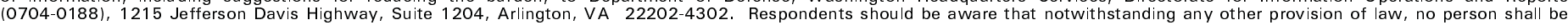
subject to any penalty for failing to comply with a collection of information if it does not display a currently valid OMB control number.

PLEASE DO NOT RETURN YOUR FORM TO THE ABOVE ADDRESS.

\section{\begin{tabular}{l|l} 
1. REPORT DATE $(D D-M M-Y Y Y Y)$ & 2. REPORT TYPE
\end{tabular} \\ 31-08-2015}

4. TITLE AND SUBTITLE

An Overview of the Technical Basis of HENRE 2.0 Models
3. DATES COVERED (From - To)

5a. CONTRACT NUMBER

HDTRA1-14-D-0003; 0005

5b. GRANT NUMBER

5c. PROGRAM ELEMENT NUMBER

5d. PROJECT NUMBER

5e. TASK NUMBER

\section{5f. WORK UNIT NUMBER}

Millage, Kyle

McClellan, Gene
8. PERFORMING ORGANIZATION REPORT NUMBER

Applied Research Associates, Inc.

801 N. Quincy Street, Suite 700

Arlington, VA 22203

\section{SPONSORING/MONITORING AGENCY NAME(S) AND ADDRESS(ES)}

Nuclear Technologies Department, Attn: Dr. Blake

Defense Threat Reduction Agency

8725 John J. Kingman Road, Mail Stop 6201

Fort Belvoir, VA 22060-6201

\section{DISTRIBUTION/AVAILABILITY STATEMENT}

DISTRIBUTION A. Approved for public release: distribution is unlimited.

\section{SUPPLEMENTARY NOTES}

\section{ABSTRACT}

This report provides an overview of the technical and scientific basis of the models incorporated in the Health Effects from Nuclear and Radiological Environments (HENRE) code for casualty estimation. The approach for each new model developed for HENRE included is presented. The models from HENRE include blast injury criteria models which are included in the Basic Casualty Estimation tool and the physiologically-based mathematical models included in the Advanced Casualty Estimation tool. In the discussion of the later tool, the aim is to provide the physiological basis for the mechanistic models included in HENRE and to highlight their application and value in casualty estimation, such as in the application to understanding the pathophysiological interactions of combined injury.

\section{SUBJECT TERMS}

RIPD, HENRE, Nuclear, Health Effects, Radiation Injury, Combined Injury, Physiological Modeling

\begin{tabular}{|c|c|c|c|}
\hline \multicolumn{3}{|c|}{ 16. SECURITY CLASSIFICATION OF: } & 1 \\
a. REPORT & b. ABSTRACT & c. THIS PAGE \\
$\mathrm{U}$ & $\mathrm{U}$ & $\mathrm{U}$ & \\
\end{tabular}

\section{LIMITATION OF ABSTRACT}

$\mathrm{U}$
18. NUMBER OF PAGES

61 19a. NAME OF RESPONSIBLE PERSON

Dr. Paul Blake, Ph.D.

19b. TELEPHONE NUMBER (Include area code)
703-767-3433 
UNIT CONVERSION TABLE

U.S. customary units to and from international units of measurement*

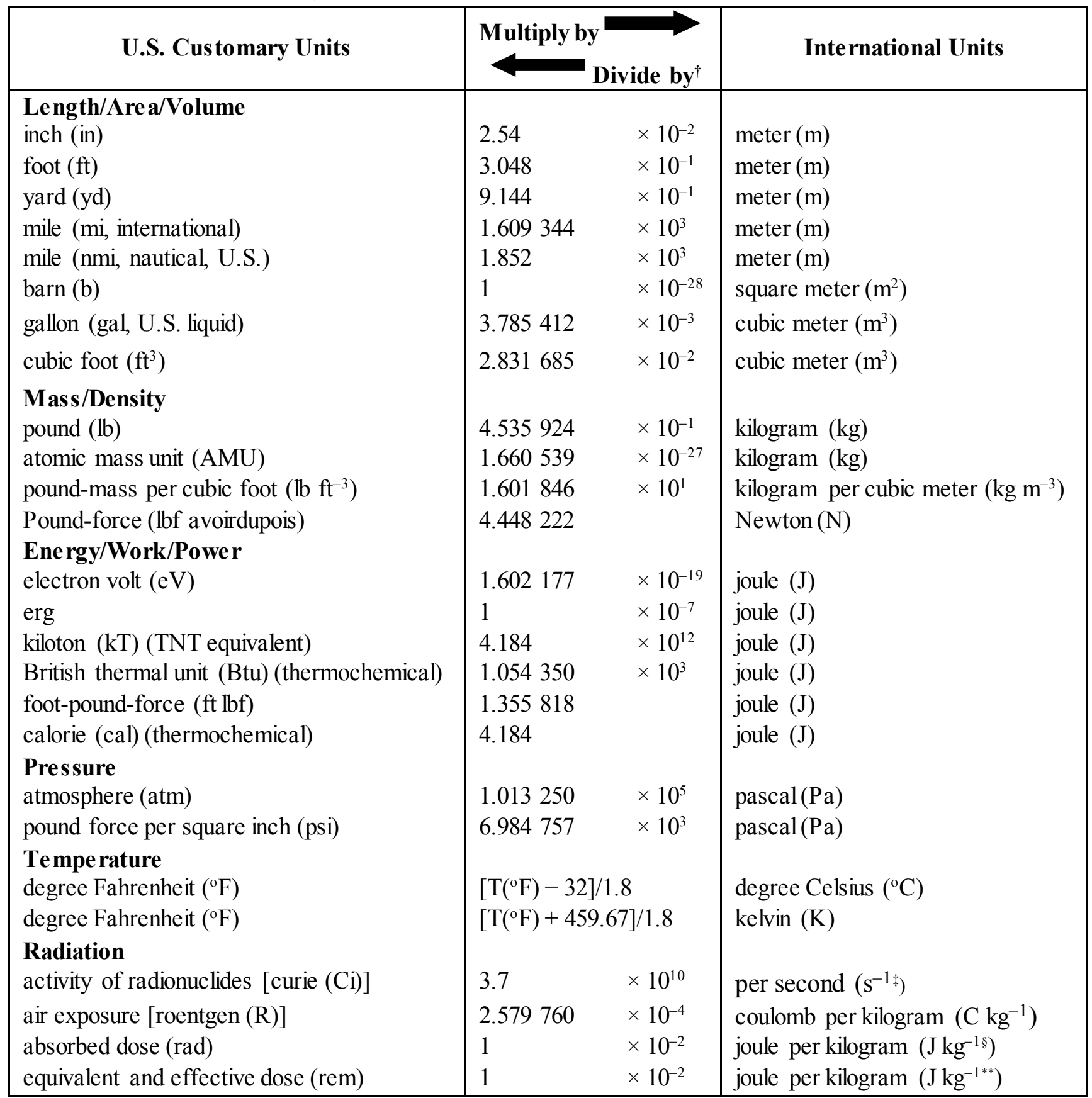

"Specific details regarding the implementation of SI units may be viewed at http://www.bipm.org/en/si/.

${ }^{\dagger}$ Multiply the U.S. customary unit by the factor to get the international unit. Divide the international unit by the factor to get the U.S. customary unit.

\$The special name for the SI unit of the activity of a radionuclide is the becquerel (Bq). $\left(1 \mathrm{~Bq}=1 \mathrm{~s}^{-1}\right)$.

${ }^{\S}$ The special name for the SI unit of absorbed dose is the gray (Gy). ( $\left.1 \mathrm{~Gy}=1 \mathrm{~J} \mathrm{~kg}^{-1}\right)$.

${ }^{* *}$ The special name for the SI unit of equivalent and effective dose is the sievert (Sv). (1 Sv $\left.=1 \mathrm{~J} \mathrm{~kg}^{-1}\right)$. 


\section{Table of Contents}

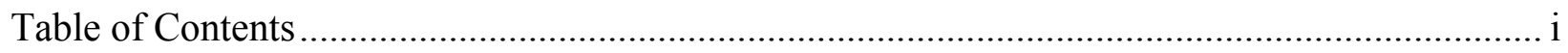

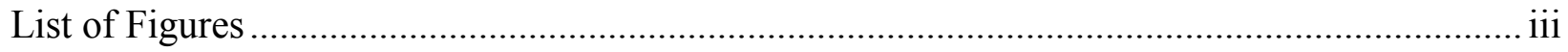

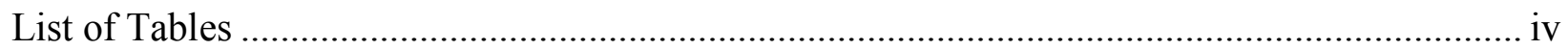

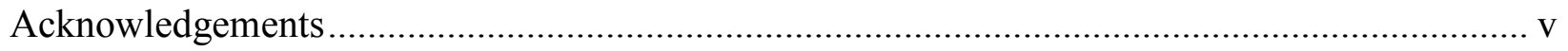

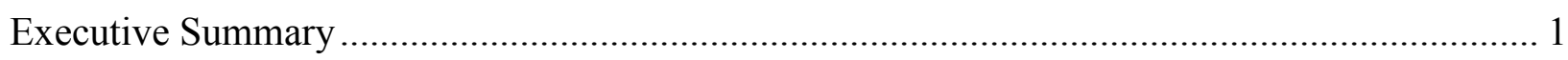

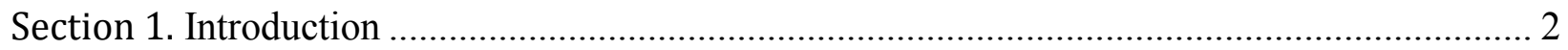

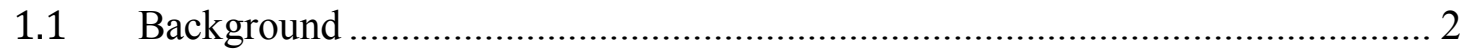

1.2 Health Effects from Nuclear and Radiological Environments (HENRE)......... 3

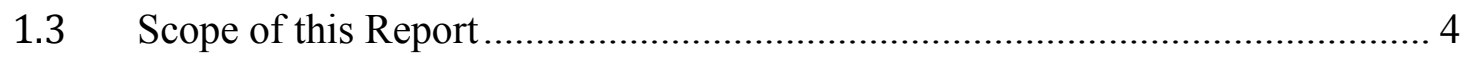

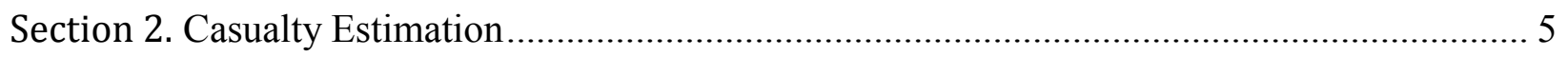

2.1 Basic Casualty Estimation..................................................................... 5

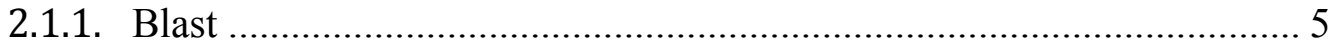

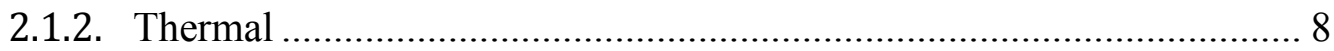

2.1.3. Radiation ................................................................................... 9

2.1.4. Combined Injury ................................................................ 10

2.2 Advanced Casualty Estimation Features................................................. 10

Section 3. HENRE Physiologically-Based Models........................................................... 12

$3.1 \quad$ Updated Radiation Injury Models ........................................................... 12

3.1.1. Hematopoietic Models ............................................................... 12

3.1.2. Small Intestine Model .................................................................... 16

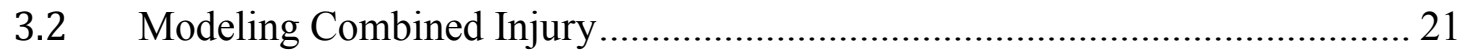

3.2.1. Modeling Boundaries .................................................................. 22

3.2.2. Modeling the Pathophysiology …................................................. 22

3.3 Risk of Circulatory Shock Estimation......................................................... 25

3.3.1. Microvascular Exchange System (MVES) Model for Thermal Injury 26

3.3.2. Integration of Radiation Permeability Changes ................................ 27

3.3.3. Combined Injury Effects ................................................................. 30

3.3.4. Risk Mapping for Circulatory Shock and 48-hour Mortality Risk ...... 31

3.3.5. Comparison of 48-hour Mortality Risks ........................................ 33 
3.4 Integration of Burn Effects into the Hematopoietic Models ......................... 34

3.4.1. Thrombopoiesis Model ............................................................ 35

3.4.2. Granulopoiesis Model ...................................................................... 36

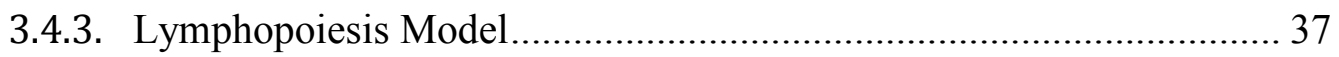

3.4.4. Combined Radiation and Burn Injury Effects................................. 38

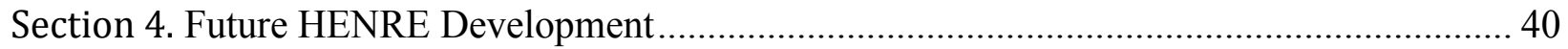

4.1 Additional Near-term Development.......................................................... 40

4.1.1. Mapping clinical endpoints to outcomes ........................................ 40

4.1.2. Integration of thermal injury effects on the GI system ..................... 41

4.1.3. Validation of models and outputs ................................................ 41

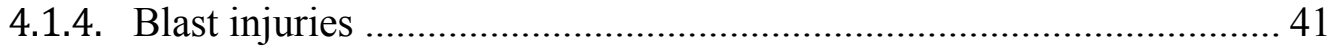

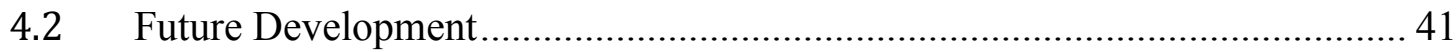

4.2.1. Modeling of traumatic injuries..................................................... 41

4.2.2. Other modeling efforts ............................................................ 42

4.2.3. Modeling of manifest GI syndrome ........................................... 43

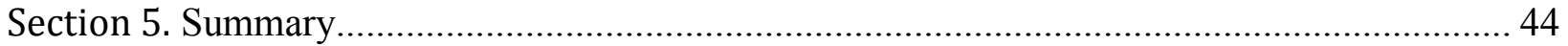

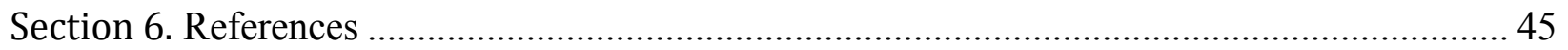

Section 7. Abbreviations, Acronyms and Symbols ................................................................. 54 


\section{List of Figures}

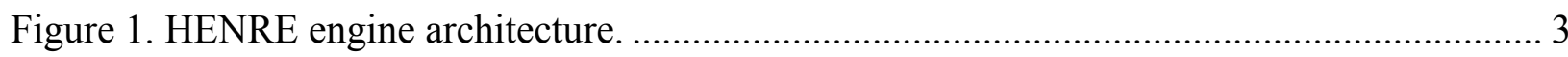

Figure 2. Model predictions compared to A.) jeep displacement data and B.) pedestrian / car

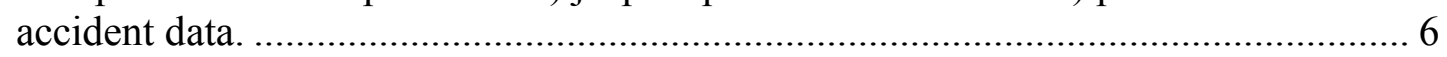

Figure 3. Predicted thrombocytes after 3 Gy with variable baseline cell levels........................... 11

Figure 4. Diagram of the generic hematopoietic model structure. .............................................. 13

Figure 5. Predicted platelet levels after prompt radiation exposure. ………………………….. 15

Figure 6. Predicted neutrophil concentrations overlaid on 2.7 Gy case study data...................... 15

Figure 7. Simulated lymphocyte depletion after 1, 3, and 5 Gy radiation exposure. .................... 16

Figure 8. Morphology of the small intestine epithelium (adapted from Velkey 2009)................ 18

Figure 9. Conceptual model of small intestinal cell dynamics.................................................. 19

Figure 10. Comparison of human model predictions with data from Trier 1966 ........................ 21

Figure 11. Interaction of pathophysiological processes in combined injury. ............................... 23

Figure 12. Timeline of effects from thermal and radiation injury......................................... 24

Figure 13. Combined radiation and burn models for HENRE (in progress or completed). ......... 25

Figure 14. Compartment model of microvascular exchange for Burn Injury (Ampratwum 1995).

Figure 15. Summary of relative permeability changes observed in experimental studies as a function of radiation dose. ................................................................................... 28

Figure 16. Simulated changes in fluid volume after different radiation doses. ........................... 30

Figure 17. Simulated changes in plasma volume after radiation, burn, and combined injury...... 31

Figure 18. Simulated minimum plasma volumes and probability of mortality as a function of $\%$ TBSA 32

Figure 19. Diagram of the generic hematopoietic model structure with burn effects. .................. 35

Figure 20. Simulated platelet concentrations for $21.5 \%$ TBSA compared to data from patients

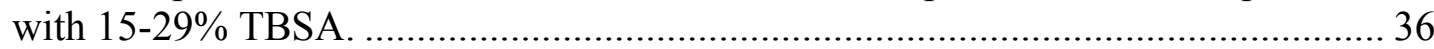

Figure 21. Simulated granulocyte concentrations for 36\% TBSA compared to data from patients with $30-50 \%$ TBSA.

Figure 22. Simulated lymphocyte concentrations for 59\% TBSA compared to data from patients

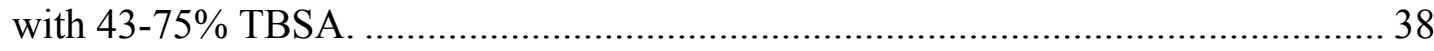

Figure 23. Simulated platelet and granulocyte concentrations after radiation, burn, and combined

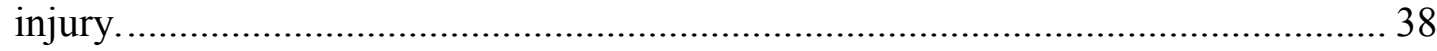




\section{List of Tables}

Table 1. Injury severity levels from blast effects............................................................. 7

Table 2. Summary of injury probit models included in HENRE 2.0 ........................................ 7

Table 3. Untreated burn mortality dose-response curves..................................................... 9

Table 4. Human radiation dose-response relationships (Anno 2003)...................................... 9

Table 5. Logistic regression models for combined injury. ............................................... 10

Table 6. Derived steady-state kinetic parameters for the jejunum in humans.......................... 19

Table 7. Derived radiation parameters for the jejunum in mice and humans............................ 20

Table 8. Organs/systems and pathophysiological processes of concern in combined injury. ...... 23

Table 9. Predicted relative permeability changes according to radiation dose and the corresponding values of $G$ for the MVES model. ............................................... 29

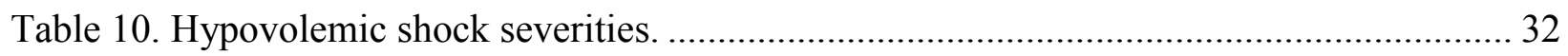

Table 11. Comparison of mortality estimates from the CSM, CI and CHRNEM models for

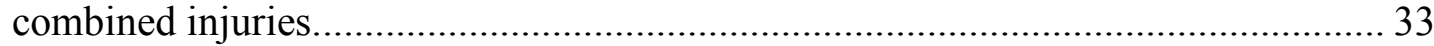

Table 12. Percent mortality predictions by MVES and CI for different combined injuries......... 34 


\section{Acknowledgements}

The authors gratefully acknowledge the technical development and/or support of the following individuals: Dr. Gene McClellan, Dr. Olga Smirnova, Dr. Ron Goans, Dr. Tom MacVittie, Dr. Vladimir Vainstein, and Dr. Glen Reeves, as well as many other researchers and collaborators. The modeling work presented in this report was built on decades of detailed and thoughtful experimental research from a variety of different scientific communities as well as previous modeling efforts.

We also gratefully acknowledge Dr. Paul Blake of DTRA/J9 for programmatic support. The work was performed under DTRA contracts HDTRA1-14-D-0003 and DTRA01-03-D-0014. 


\section{Executive Summary}

This report provides an overview of the technical and scientific basis of the models incorporated in the Health Effects from Nuclear and Radiological Environments (HENRE) code. This report describes the current release of the HENRE tool incorporate models developed for casualty estimation associated with prompt environments generated from a nuclear detonation. Two suites of models are included in the HENRE tool; the Basic Casualty Estimation Tool and the Advanced Casualty Estimation Tool and this report describes the rationale and approaches used for each new model that has been implemented.

The HENRE suite of models includes the Radiation-Induced Performance Decrement (RIPD) code; however, this report does not review the RIPD models since that set of models have been thoroughly documented, reviewed, and summarized elsewhere. The models implemented in HENRE include blast injury criteria models which are implemented in the Basic Casualty Estimation tool and the physiologically-based mathematical models included in the Advanced Casualty Estimation tool. In the discussion of the latter tool, the aim is to provide the physiological basis for the mechanistic models included in HENRE and to highlight their application and value in casualty estimation. For example, mechanistic model have been applied to better understand the complex pathophysiological interactions of combined injury and to more precisely predict combined injury outcomes.

This report describes the background and implementation of the current models in the HENRE 2.0 version as of the publication date of this report. New models and capabilities will continue to be added to HENRE and near-term plans and future modeling needs are also discussed.

Note that the HENRE software code has distribution restricted to authorized U.S. government users and contractors. It is available upon request from the DTRA Program Manager, Code J9NTSN; see Report Documentation Page (SF 298) in the front of this report for contact information. 


\section{Section 1.}

\section{Introduction}

\subsection{Background}

As part of its mission to safeguard against weapons of mass destruction (WMD), the Defense Threat Reduction Agency (DTRA) supports the development of capabilities to reduce, eliminate and counter WMD threats and mitigate their effects. Applied Research Associates, Inc. (ARA) has supported DTRA's mission by developing state-of-the-art mathematical models that predict medical and performance consequences from radiation and combined injuries, thereby enhancing our understanding of the potential impact of a nuclear detonation. We have improved current casualty estimation capabilities through an interdisciplinary approach that integrates experimental data with mechanistic mathematical modeling. A mechanistic model of acute radiation sickness based on physiology was undertaken in the 1990s. The result was the Radiation-Induced Performance Decrement (RIPD) set of models, which were integrated into a software tool used for planning and scenario predictions for nuclear detonations (Matheson 1998). RIPD addressed a number of important needs for more accurate casualty estimation, including dose rate effects for protracted exposures from fallout and time course severity of clinical signs and symptoms (Pellmar 2012a). Briefly, the RIPD models estimate:

- Health effects from prompt or protracted neutron and gamma total free-in-air (FIA) doses between 0.75 and 45 Gy.

- Probability of mortality and time to mortality.

- Time-dependent clinical signs/symptoms and severity of illness.

- Clinically relevant parameters such as minimal hematopoietic cell counts and cell loss in the gut mucosa.

- Resulting performance decrement.

However, a number of gaps remain in DTRA's existing nuclear detonation casualty estimation approaches. Some of these gaps reside in the injury criteria models that are currently used. Current models used in tools like DTRA's Hazard Prediction and Assessment Capability (HPAC) rely on range to effect relationships dependent on weapon yield and distance. However, since those relationships were developed from data obtained in open-field tests, they do not adequately account for non-ideal scenarios, such as urban environments, that are predominate for today's planning. Other issues with injury criteria models reside in the level of detail provided in the estimated injuries. For example, the number of specific injury types, such as open wounds, bone fractures, blunt trauma, and concussions, etc. can provide valuable information for medical resource planning. Finally, many of the injury criteria models used today were developed decades ago and the source data for some models is not well documented. More recent experiments from the blast community and data obtained in other injury risk assessment areas, as well as modern computation models (such as glass breakage models), can provide valuable contributions to improved casualty estimation. 
Estimating the health impacts of combined injury is another area in which current casualty estimation approaches could be improved. A number of diverse injuries are anticipated in nuclear detonation scenarios, including blunt trauma, open wounds, and burns, all of which could be complicated by microbial infection. Historical data from Hiroshima show that $65-70 \%$ of injured persons are expected to have combined injuries (Geiger 1964, Goans 2009). Experimental data has shown that radiation, combined with other injuries, shortens the onset of symptoms, exacerbates symptoms, causes synergistic increases in mortality, and impairs wound healing (Messerschmidt 1965, Baum 1991). To improve our understanding of human response to combined injury, updated models of radiation combined injury are needed. The existing combined injury model, Consolidated Human Response Nuclear Effects Model (CHRNEM), is based strictly on empirical descriptions of signs and symptoms as developed by subject matter experts (SMEs) (Levin 1993b) and lacks descriptions of the physiological mechanisms behind injury. Because the different injury types may impact physiological mechanisms in a variety of ways, mechanistic modeling can help us understand these complicated interactions and estimate the potentially synergistic effects of combined injury (Stricklin 2010a). Mechanistic models of injury provide a means to describe the time course of injury and potentially how medical countermeasures can impact injury outcomes.

\subsection{Health Effects from Nuclear and Radiological Environments (HENRE)}

To address some of the current limitations in prompt casualty estimation for nuclear detonation scenarios, ARA updated and documented new injury criteria and health effects models. The new models have been integrated into the new software code, Health Effects from Nuclear and Radiological Environments (HENRE) (Oldson 2013). HENRE is a software code, with distribution restricted to authorized U.S. government users and contractors. It is available upon request from the DTRA Program Manager, Code J9-NTSN; see Report Documentation Page (SF 298 ) in the front of this report for contact information.

HENRE includes all of the previous RIPD codes which have been re-written, documented, and integrated in a modern, flexible architecture (see Figure 1) that is amenable to integration of new models as they become available. HENRE also has been integrated with several new models, such as modified injury criteria models and new and updated physiological models for estimating radiation and thermal combined injury effects. The suite of models included in HENRE to date are:

- $\quad$ RIPD 5.2

- Time-dependent lethality from radiation exposures

- Performance decrement

- Time course and severity of clinical signs and symptoms

- Injury Criteria Models

- Probability of injury for blast effects

- Percent of total body surface area (\% TBSA)

- Additional Human Response Models

- Lethality from thermal injury

- Lethality from combined radiation and thermal injury

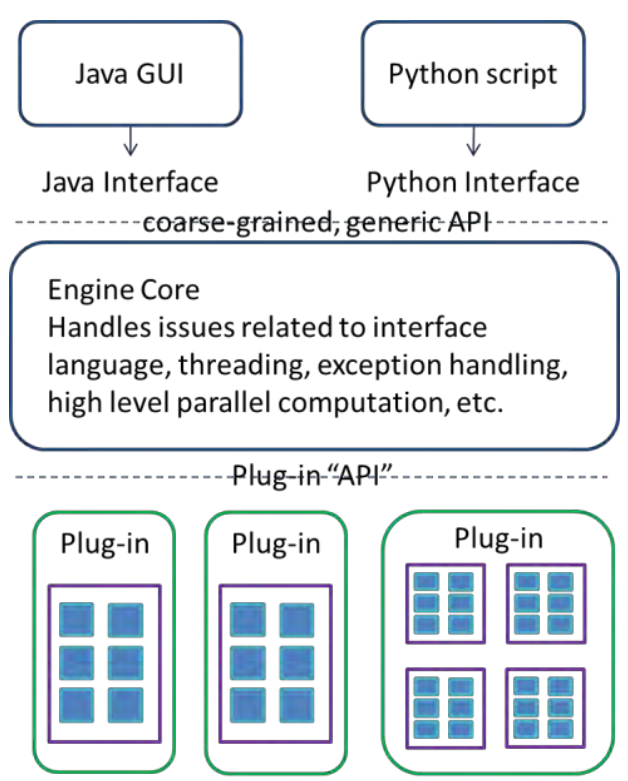

Figure 1. HENRE engine architecture. 
- Updated Physiological Models for Radiation Effects

- Hematopoietic models

- Small intestine model

- New Physiological Models

- Microvascular exchange model: burn shock and combined injury

- Hematopoietic models: burn and combined injury

\subsection{Scope of this Report}

The purpose of this report is to provide an overview of the models in HENRE that includes the technical basis of the models, required inputs, outputs generated, important attributes, and known limitations of the models. This report does not cover the models included in RIPD 5.2 since its models have been described elsewhere (Anno 1984, Baum 1984, Anno 1985, Anno 1989, Anno 1991, Anno 1994, Anno 1996, Jones 1996, Matheson 1998, Anno 2003) and the RIPD models as incorporated in HENRE have recently been reviewed (Pellmar 2012a), and documented (Oldson 2015).

The descriptions of the models provided in this report are an overview of the important details of the models and how they function. Detailed descriptions of the models are published elsewhere and referenced as appropriate. 


\section{Section 2.}

\section{Casualty Estimation}

\subsection{Basic Casualty Estimation}

The Basic Casualty Estimation tab in HENRE enables the estimation of prompt casualty effects from blast, thermal, radiation, or combined radiation/thermal environments. The environments are defined in terms of the following:

- Blast: peak overpressure and duration of positive overpressure

- Thermal: thermal fluence

- Radiation: prompt gamma dose and/or prompt neutron dose

Outputs include:

- Probability of injury (blast effects)

- Probability of lethality (radiation, thermal, and combined injury)

- Time of lethality

- Probability of lethality assuming standard care (radiation)

An interim goal of our work has been to integrate additional injury models, including injury criteria models for predicting casualties based on nuclear environment inputs, into the suite of models available in HENRE. This goal will enable HENRE to estimate a complete set of prompt effect predictions that can be integrated in nuclear effects codes as an optional casualty estimation tool in the future. Because HENRE has advanced features that require more computational time, it is proposed as an optional tool when higher fidelity information is needed in a scenario analysis.

The additional models have been integrated in HENRE's Basic Casualty Estimation tab which requires nuclear weapons environment inputs. Therefore, as a standalone tool, non-DoD personnel would not be expected to use this tab, and it may be disabled when sharing with interested civilian agencies. The HENRE code, however, should be integrated into the HPAC platform in the future, where it will be connected with other nuclear effects codes to provide the necessary inputs required for casualty estimation.

Medical planners and civilian analysts interested primarily in estimating physiological effects and medical resource requirements, etc. will be directed to the Advanced Casualty Estimation tab.

\subsubsection{Blast}

Calculating the probability of secondary or tertiary injury due to blast is a two-step process: (1) human or missile velocities are determined based on blast wave parameters and (2) probit models relate the velocity of an object to the probability of injury. 


\subsubsection{Translation Model}

The Personnel Risk and Casualty Criteria (PRCC) report and Effects Manual-1 Chapter 14 (EM1 Ch. 14) provide starting points for this endeavor (DoA 2013, Drake 1993, Reeves 2015).

These documents use look-up tables developed in the 1970s to determine the velocity of a human or missile, based on peak overpressure and yield (Fletcher 1975). However, this method is not accurate when considering the complex waveforms that occur in urban environments. To address this issue, we have adopted and implemented the original translation model developed by Lovelace Foundation for Medical Education and Research (LFMER; Bowen 1961, Fletcher 1966) to predict the velocity of objects based on the incident-specific blast wave parameters. The translation model uses the following inputs: the dynamic pressure wave, the time course of the wind velocity, and the acceleration coefficient of the object of interest. The acceleration coefficient is a function of the object's mass, area presented to the wind, and drag coefficient. With these inputs, the model calculates the translational profile (i.e., distance, velocity, and acceleration) as a function of time. This allows for more accurate calculation of an object's velocity from complex blast waves. The details of the model, its implementation, and its validation have been recently published (Wentz 2015a, Oldson 2015). Two examples of the validation of the models with modern data are presented in Figure 2. Model predictions (A) using the minimum and maximum displacement using the dynamic pressure impulse were compared to jeep displacement data obtained from Needham 2010. For qualitative validation of the deceleration portion of the model, data on the displacement of pedestrians in car accidents (Otte 2001) were compared to model predictions (B) assuming initial velocities were equivalent to the velocity of the vehicle on impact.
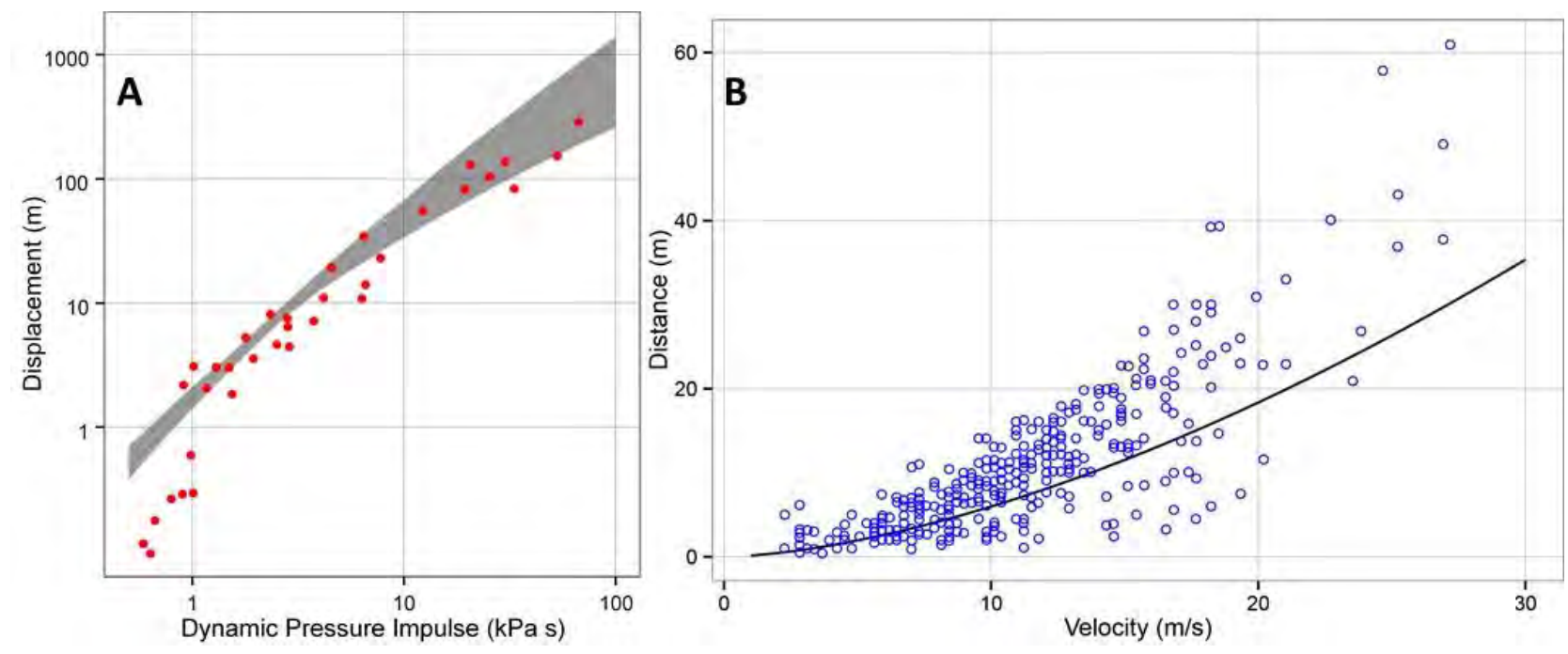

Figure 2. Model predictions compared to A.) jeep displacement data and B.) pedestrian / car accident data.

\subsubsection{Injury Probit Models}

The object velocity is then used to estimate likelihood of injury through the use of probit models. Table 1 summarizes the injury severity level definitions for the output of the models. 
Table 1. Injury severity levels from blast effects.

\begin{tabular}{ll}
\hline Injury Level & Description \\
\hline Fatal Injury (FI) & Injury resulting in death \\
Serious Injury (SI) & Fractured bones or ruptured internal organs \\
Moderate Injury (MI) & Multiple lacerations/contusions due to small \\
& missiles \\
Combat Ineffectiveness (CIn) & Performance decrement greater than 75\% \\
\hline
\end{tabular}

The existing probits relating velocity to injury are based on limited data. Due to the many assumptions involved in the generation of the existing probit models, where possible, new probit models were developed using more recent data for model extrapolation. The models included in HENRE 2.0 are summarized in Table 2.

Table 2. Summary of injury probit models included in HENRE 2.0.

\begin{tabular}{|c|c|c|c|}
\hline & Fatal Injury & Serious Injury & Moderate Injury \\
\hline $\begin{array}{l}\text { Decelerative Tumbling } \\
\text { (Urban Environment) }\end{array}$ & $\begin{array}{l}\text { if } v \leq 46.01 \mathrm{~m} / \mathrm{s} \text {; } \\
2.86 \log _{10}\left(\frac{v}{V_{s 0}}\right) ; \\
V_{50}=40.19 \frac{\mathrm{m}}{\mathrm{s}} \\
\text { if } v>46.01 \mathrm{~m} / \mathrm{s} \text { : } \\
19.55 \log _{10}\left(\frac{v}{V_{101}}\right) ; \\
V_{50}=45.11 \frac{\mathrm{m}}{\mathrm{s}}\end{array}$ & $\begin{array}{l}\text { if } v \leq 32.37 \mathrm{~m} / \mathrm{s}: \\
2.40 \log _{10}\left(\frac{v}{V_{50}}\right) ; \\
V_{\mathrm{t} 0}=9.22 \frac{\mathrm{m}}{\mathrm{s}} \\
\text { if } v>32.37 \mathrm{~m} / \mathrm{s}: \\
6.42 \log _{10}\left(\frac{v}{V_{\mathrm{m}}}\right) ; \\
V_{\mathrm{t} 0}=20.24 \frac{\mathrm{m}}{\mathrm{s}}\end{array}$ & None \\
\hline $\begin{array}{l}\text { Decelerative Tumbling } \\
\text { (Open Field) }\end{array}$ & $\begin{array}{l}19.55 \log _{10}\left(\frac{v}{v_{00}}\right) \\
V_{50}=45.11 \frac{\mathrm{m}}{\mathrm{s}}\end{array}$ & $\begin{array}{l}6.42 \log _{10}\left(\frac{v}{V_{50}}\right) ; V_{300}= \\
20.24 \frac{\mathrm{m}}{5}\end{array}$ & None \\
\hline Perpendicular Impact & $\begin{array}{l}7.19 \log _{10}\left(\frac{v}{V_{p}}\right) \\
V_{\mathrm{t} 0}=15.35 \frac{\mathrm{m}}{\mathrm{s}}\end{array}$ & $\begin{array}{l}4.84 \log _{10}\left(\frac{v}{V_{50}}\right) ; V_{50}= \\
8.61 \frac{\mathrm{m}}{\mathrm{s}}\end{array}$ & None \\
\hline Glass Penetration & None & $\begin{array}{l}2.85 \log _{10}\left(\frac{m^{0 . a_{v} v^{2}}}{2 F_{50}}\right) ; \\
F_{30}=89.45 \frac{\mathrm{kg}^{0 . F_{m^{2}}}}{s^{2}}\end{array}$ & $\begin{array}{l}2.85 \log _{10}\left(\frac{\mathrm{m}^{0.5 v^{2}}}{2 F_{50}}\right) ; \\
F_{50}=44.93 \frac{\mathrm{kg}^{0.5} \mathrm{~m}^{2}}{\mathrm{~s}^{2}}\end{array}$ \\
\hline Stone Penetration & None & None & $\begin{array}{l}2.85 \log _{10}\left(\frac{\mathrm{m}^{0.5} v^{2}}{2 F_{\mathrm{ra}}}\right) ; \\
F_{50}=178.5 \frac{\mathrm{kg}^{0.5} \mathrm{~m}^{2}}{\mathrm{~s}^{2}}\end{array}$ \\
\hline Blunt Trauma & None & $\begin{array}{l}2.51 \log _{10}\left(\frac{E}{E_{50}}\right) \\
E_{50}=67.37 \mathrm{~J}\end{array}$ & None \\
\hline
\end{tabular}

Secondary injuries are caused by missiles that are accelerated by the blast wave. Tertiary injuries are caused by the acceleration of the human body and the ensuing deceleration. Probits for FI and SI are included for tertiary injury, and probits for SI and MI are included for secondary injury. These recommendations are based on a thorough review of the existing injury criteria models used by the nuclear effects community.

For FI and SI due to decelerative tumbling, existing models and new data were evaluated. Motorcycle accident data (Hurt 1981a, Hurt 1981b) provided more verifiable and accurate representation of injury probabilities that might be observed in an urban environment. 
Therefore, a probit model was derived using motorcycle data and incorporated into HENRE 2.0 to predict injury in urban environments at lower velocities (for which the data was representative). Of the existing models, the probit model from EM-1 Ch. 14 was the most adequately described and included in HENRE 2.0 to predict decelerative tumbling injuries in open field environments as well as injuries in urban environments at high velocities (Reeves 2015). Due to the limited data and documentation for CIn and MI models, they are not currently included and warrant future investigation.

Data from more recent human free fall studies (Lapostolle 2005, Beale 2000, Dickinson 2012) were used to develop new probit models for FI and SI due to perpendicular impact with a nonyielding surface. These models are an improvement to the existing models which are, in part, extrapolated from limited animal data (DoA 2013, Drake 1993, Mercier 2001). Again, limited data and documentation on CIn and MI do not warrant their inclusion at this time.

New probit models were developed for penetration injury using the same source data as the PRCC report that includes the mass of the object in the probit equation. The likelihood of a missile penetrating the skin was assumed equivalent to MI and the likelihood of a missile penetrating the abdomen was equivalent to SI.

Although we could not find the source documentation (Zuckerman 1944), the only probit model for blunt trauma (SI), which was based on data obtained by performing impact studies with small animals and dried human skulls (Drake 1978), was included.

\subsubsection{Thermal}

No advanced development of estimating thermal injury has been conducted. Currently, the approach provided by AMedP-8(C) (NATO 2011) is used to translate thermal fluence environment inputs to the burn insult parameter percent total body surface area affected by burn (\% TBSA). The calculation is:

$$
T B S A=\left(\frac{\cos ^{-1}\left(Q_{\text {uniform }}^{T} / Q\right)}{\pi}\right) \cdot P_{\text {uniform }}+\left(\frac{\cos ^{-1}\left(Q_{\text {bareskin }}^{T} / Q\right)}{\pi}\right) \cdot P_{\text {bareskin }}
$$

where $T B S A$ is the percent total body surface area affected by the burn injury, $Q^{T}$ uniform is the thermal fluence threshold value for a specific military uniform type ${ }^{1}$ for a partial-thickness (second degree) burn, and $Q^{T}$ bareskin is the thermal fluence threshold value for bare skin for a partial-thickness (second degree) burn.

Once \% TBSA is calculated, the probability of mortality is calculated based on probit models developed from case study data on patients in which advanced care was not available (Stricklin 2012b, Bull 1949, and Bull 1954). The probit models relates \% TBSA to 48-hour or 30-day mortality, for the case in which no specialized care is provided. Table 3 provides the probit model parameters for burn mortality in terms of the lethal area (LA) in which 10,50 , or $90 \%$ of the population would die. The input to the probit equation, $x$, is $\%$ TBSA.

\footnotetext{
${ }^{1}$ e.g. Battledress Uniform (BDU)
} 
Table 3. Untreated burn mortality dose-response curves.

\begin{tabular}{lcccc}
\hline Model & LA $_{10}$ & LA $_{50}$ & LA $_{90}$ & Equation \\
\hline \hline $\begin{array}{l}\text { Untreated, 48-hr burn } \\
\text { mortality }\end{array}$ & 23 & 45 & 67 & $y=-2.59827+0.05868 x$ \\
$\begin{array}{l}\text { Untreated, 30-day burn } \\
\text { mortality }\end{array}$ & 14 & 31 & 48 & $y=-2.3531+0.0765 x$ \\
\hline
\end{tabular}

\subsubsection{Radiation}

\subsubsection{Lethality without treatment}

For radiation exposure only assuming no specialized care, probability of lethality is estimated using the same methodology as is used in the RIPD tool. Specifically, probability of lethality for prompt exposures is estimated using a probit model (Anno 2003), and this model is extended to protracted exposures by estimating an equivalent prompt dose based on a minimal cell count from a bone marrow cell kinetic model, MarCell (Jones 1996). These models have been reviewed and presented previously (Pellmar 2012a). The time to lethality predictions from radiation alone are based on empirical data that were fit according to SMEs and their knowledge of mortality observed after radiation accidents and from the experience in Nagasaki and Hiroshima.

\subsubsection{Modified lethality with standard care}

Existing casualty estimation tools calculate probability of mortality assuming no medical treatment is available. However, even without advanced care, the lethality of radiation can be modified by the use of standard medical treatments based on observed clinical signs and symptoms. These standard care practices can vary, but in general include antiemetics, IV fluids, antibiotics, and blood products during periods of cytopenia. The data available on the modification of standard care in human and different animal radiation lethality has recently been reviewed (Stricklin 2015). Significant variability and uncertainty exists in the existing data, and further analysis is warranted. For now, the dose response reported by Anno 2003, which based on lethality observed in the Chernobyl cohort, appears the most relevant and justified model available and has been implemented in HENRE. Therefore, the lethality of radiation only scenarios can be compared between no care and standard care, as shown in Table 4, where D is the FIA radiation dose in units of Gy.

Table 4. Human radiation dose-response relationships (Anno 2003).

\begin{tabular}{lc}
\hline Type of Dose-Response Relationship & Probit Equation \\
\hline \hline No medical care & $p=-4.4011+7.133 \log _{10} D$ \\
Standard care & $p=-5.6571+7.133 \log _{10} D$ \\
\hline
\end{tabular}




\subsubsection{Combined Injury}

For combined radiation and thermal injury, the probability of lethality is estimated for the first 48 hours and then for 30 days. The 48 -hour combined injury lethality is based on the 48 -hour burn lethality model (2.1.2), which is a probit model that estimates the risk of death from circulatory shock after burn injury, assuming no advanced treatment. This 48-hr mortality probabilities are equated to the plasma volume minimums associated with different $\%$ TBSA of burn injury. The plasma volume minimums are estimated by a microvascular exchange model, described in 3.3.1, and the associated mortality probability for the plasma volumes are used to predict mortality when radiation is combined with burn. This extrapolation only holds for the 48-hr mortality risk.

Due to uncertainty in radiation effects on the vascular epithelium at high doses of radiation, a statistical model is used to predict lethality from radiation dose greater than about $4 \mathrm{~Gy}$. The combined injury probit model was adapted from experimental animal data on combined injury (Alpen 1954, Baum 1991), which were extrapolated based on comparable equivalent human doses for each of the exposures used in the animal studies (Stricklin 2013c). The extrapolations were made using known dose-response curves for each species and each insult, radiation and burn. For 4 to 30 day lethality predictions from combined radiation and thermal injury, a statistical model based on the same extrapolated animal data as described above is currently used. The statistical combined injury models are listed in Table 5; the inputs are in terms of $\%$ TBSA, $x$, and radiation dose, $D$, in Gy.

Table 5. Logistic regression models for combined injury.

\begin{tabular}{lc}
\hline Model & Equation \\
\hline 48 -hr CI & $y=-1.98152+0.05966 x+0.51349 D$ \\
4 to 30-day CI & $y=-2.53686+0.06196 x+1.61183 D$ \\
\hline
\end{tabular}

More detailed predictions of lethality from combined injury based on extrapolations from mechanistic model outputs will be implemented as they become available. These mechanistic models will provide higher fidelity in the time to mortality estimate.

\subsection{Advanced Casualty Estimation Features}

The Advanced Casualty Estimation tab in HENRE enables the estimation of more detailed effects from burn, radiation, or combined radiation and burn injury. The inputs include:

- Thermal: \% TBSA affected by burn injury

- Radiation: prompt gamma dose and/or neutron dose (Gy)

Outputs of the Advanced Casualty Estimation tool include:

- Probability of lethality

- Time of lethality

- Probability of lethality assuming standard care (radiation only) 
- Early changes in plasma volumes

- Circulating hematopoietic cell levels

The advanced features allow evaluation of clinically relevant parameters that impact medical planning and provide detailed information regarding the time course of injury. These outputs are made available by the mechanistic models incorporated in HENRE. Other outputs from these models may be made available as needed. A more detailed discussion of the mechanistic models in HENRE and their basis are provided in Section 3.

Other computational features are beginning to be incorporated in the advanced mode. For example, some parameters vary among populations, such as baseline blood cell counts. Simulations can examine this variability by running the model a specified number of times, sampling the known distribution of that parameter. The output then shows the expected response given the variance in that parameter. Figure 3 illustrates a simulation of $3 \mathrm{~Gy}$ gamma exposure, in which the baseline cell count was sampled around a distribution. These simulations can provide the user with an idea of the variability one might expect to observe in an actual population.

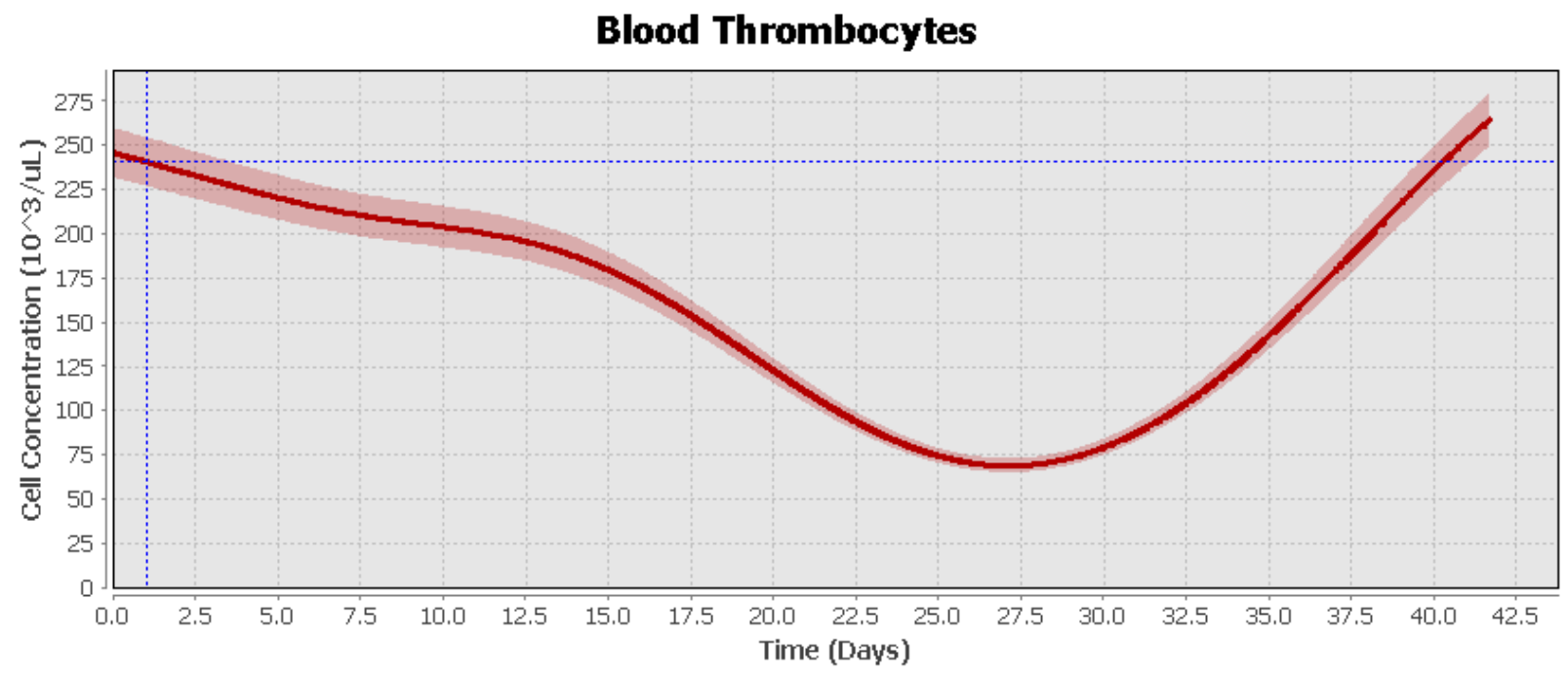

Figure 3. Predicted thrombocytes after $3 \mathrm{~Gy}$ with variable baseline cell levels. 


\section{Section 3.}

\section{HENRE Physiologically-Based Models}

\subsection{Updated Radiation Injury Models}

Several of the models implemented in RIPD have been recently updated to address known issues and enable further modeling, i.e. interactions with other injury types, other organ system effects, and eventually the impact of advanced medical treatment.

\subsubsection{Hematopoietic Models}

Hematopoiesis is the process of mature blood cell generation and is initiated in the bone marrow by hematopoietic stem cells (HSC). The three cell types modeled here are platelets (thrombocytes), granulocytes (neutrophils), and lymphocytes. These cells play essential roles in immunity and maintaining a healthy state. Perturbations to their equilibrium concentrations can have detrimental effects. Radiation doses above about 1 Gy have a significant impact on the blood cells, their progenitor cells, and blood cell dynamics. Radiation can directly damage blood cells and impact proliferation by directly killing early progenitor cells and perturbing hematopoiesis through mediator-related processes. A more detailed description of hematopoiesis and the impact of radiation, as well as burn, on blood cell kinetics is provided in a recent review by Pellmar and Reeves (Pellmar 2012b).

Mathematical models can be used to better understand the impacts of radiation on blood cell dynamics, depletion of different cell lines, and the timeframe of recovery. More detailed models of blood cell dynamics, which include mechanism descriptions, make it possible to also understand how other insults, such as burn, impact those dynamics and potentially exacerbate the injury's pathophysiology. Therefore, existing models of hematopoietic dynamics were updated, fully documented, and validated (Wentz 2014, Wentz 2015e).

A number of models exist that describe the kinetics of different blood cell lineages. Smirnova's previously published models of thrombopoiesis, granulopoiesis, and lymphopoiesis after prompt radiation exposure (Smirnova 2010, Smirnova 2012), which describe the effect of radiation on blood cell dynamics, were updated by collecting experimental data on as many parameters as possible. These parameters include data compartment sizes, transition rates, cell life span, and radiosensitivity, for example. In this way, the model is supported by established biological parameters while as few as possible parameters were developed from fitting and optimization procedures. The original model structures were re-engineered so that the mediator impact serves as a stimulatory effect rather than an inhibitory effect on cell proliferation (Wentz 2014, Wentz 2015e). In fact, different mediators exist and regulate proliferation by up-regulation and downregulation. However, the stimulatory regulation provides a mechanism to integrate other injuries and/ or treatment that impacts proliferation through up-regulation.

Also, in Smirnova's original model, cell damage is modeled using the one-target-one-hit theory of cell damage, in which the specific rate of damage is proportional to the radiation dose (Joiner 2009). After acute radiation of dose $D$, the proportion of undamaged or surviving cells is:

$$
S=e^{-D / D_{i}^{0}}
$$


However, this model is limited in its ability to capture the dose-response characteristics of cell survival. Therefore, we have implemented a more general cell survival model, the multi-targetsingle-hit model (Joiner 2009). In this model, the surviving fraction of cells after acute radiation of dose $D$ is

$$
S=1-\left(1-e^{-\frac{D}{D_{i}^{0}}}\right)^{n i}
$$

where $n_{i}$ is the average number of hits required to damage a cell in the compartment and $D_{i}^{0}$ is the dose that results in (on average) one hit per target. As expected, when $n_{i}=1$ this model simplifies to the one-target-one-hit model. Thus, for each radiosensitive cell group, there are two parameters that determine the proportion of cells that are undamaged: $D_{i}^{0}$ and $n_{i}$.

In addition to the model modifications, we collected a wide range of human data which we partitioned; we used one set of data to optimize the modified models and another set of data to validate the resulting models outputs.

\subsubsection{General Hematopoietic Model Structure}

The generic model structure is shown in Figure 4, which illustrates how hematopoiesis is initiated in the bone marrow by dividing progenitor cells. These transition into non-dividing progenitor cells, which then become mature cells in the blood. Radiation causes cells to enter damaged states from which the cells eventually die.

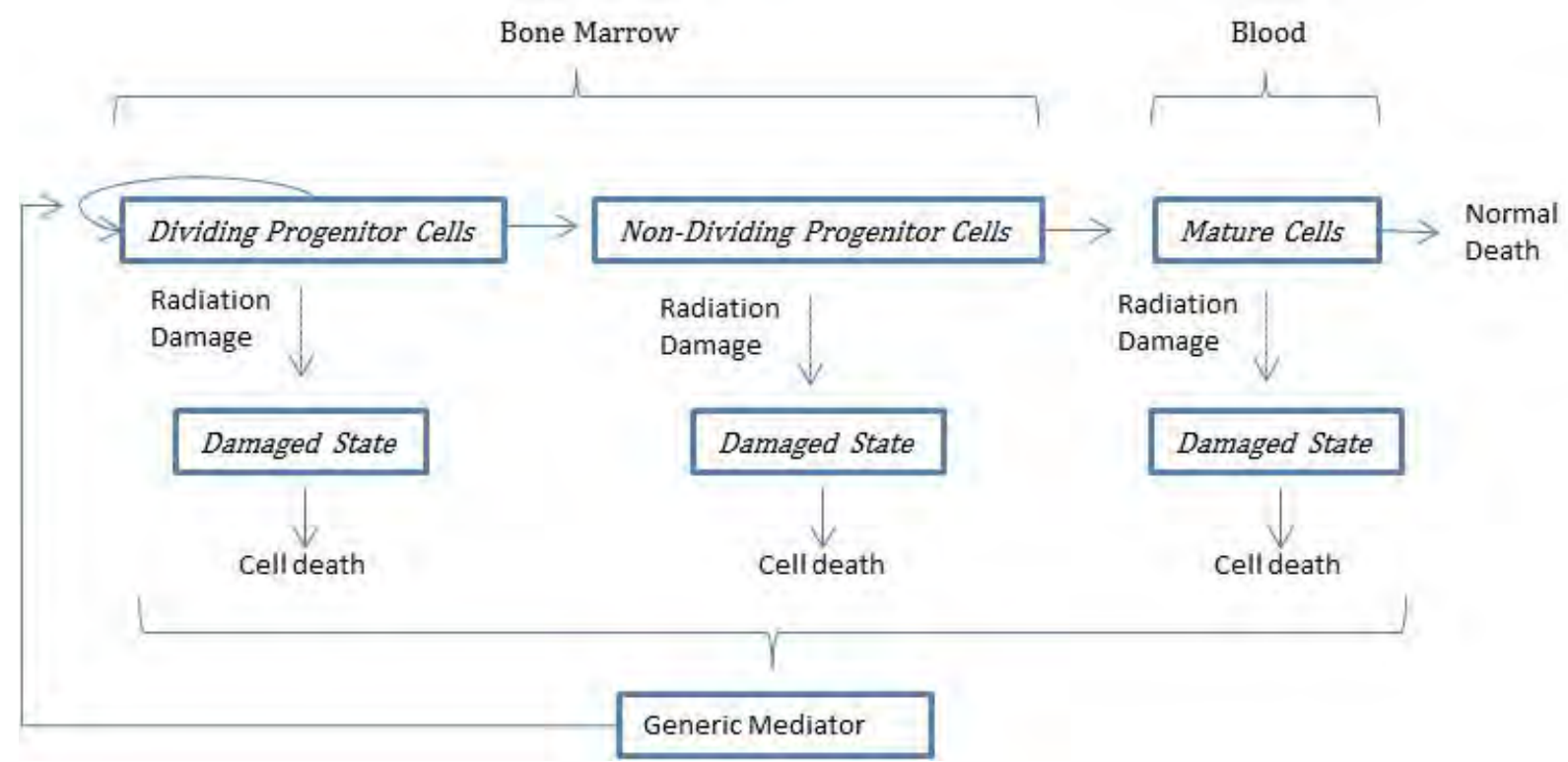

Figure 4. Diagram of the generic hematopoietic model structure.

This model describes blood cell formation, which is initiated within the bone marrow by dividing progenitor cells. Following a series of divisions, the mitotic cells differentiate into non-mitotic cells. The non-dividing cells eventually produce mature cells that exit the bone marrow and enter the blood. All cells in the system contribute to the decay of a generic mediator that stimulates the repopulation of the dividing progenitor cells. Hence, as the cell populations increase, there is 
a negative feedback which reduces cell production in order to maintain equilibrium. Acute radiation causes radiosensitive cells to enter damaged states, from which the cells eventually die.

For a more detailed description of the model structure, including specifics on how the three models differ see DTRA-TR-14-31 (Wentz 2014). This report also details all of the mechanisms, data, and parameters, which the models are based on, as well as the procedures and data used in optimization and validation of the models.

\subsubsection{Thrombopoiesis Model}

Thrombopoiesis is the process of platelet formation. Platelets are responsible for the coagulation of blood and are a source of growth factors, which regulate cell growth and division. Platelet generation is initiated by self-renewing hematopoietic stem cells (HSCs) in the bone marrow. These stem cells differentiate and, through a series of mitotic divisions, produce megakaryocytes (MKs), the precursors of platelets. As MKs mature, their ploidy increases, through a series of endomitoses. Once mature, MKs produce platelets which enter the blood stream. Similar to the baseline model structure, the thrombopoietic model consists of three compartments.

The first compartment represents mitotic precursors in the bone marrow, ranging from HSCs to megakaryoblasts. The second compartment represents MKs in the bone marrow, and the third compartment represents platelets in circulation. Each MK produces thousands of platelets, resulting in amplification. Following radiation exposure in humans, there is a delay before the peripheral platelet counts start to decline (Bond 1965). This delay is, in part, due to the time needed for the early progenitors affected by radiation to mature. In order to simulate this delayed effect, sub-compartments were added to the MK compartment. A cell entering the second compartment travels through each of the subcompartments before producing platelets. Furthermore, the first half of the MK subcompartments are considered immature MKs and the second half are considered mature MKs. The reason for this differentiation is for feedback purposes. The platelet compartment is also divided into subcompartments to generate more biologically realistic transit time distributions (Murphy 1971).

In Smirnova's original model, MKs were considered radioresistant. However, both mitotic progenitors and MKs are considered radiosensitive in our model. MK radiosensitivity was added to better describe the lack of delay in platelet decline after higher radiation doses (5-8 Gy). The lack of delay in platelet decline at high doses suggest that some portion of MKs are damaged (Cohn 1956). The original model also contained moderately, heavily, or weakly damaged cell compartments, which may have been required for adequately modeling protracted radiation response. However, having multiple damaged cell compartments did not significantly affect model outputs. Therefore, to simplify the model and minimize parameters, the weakly damaged cell compartments were removed, and the moderately and heavily damaged cell compartments were merged into one damaged compartment.

The thrombopoeisis model predicts circulating platelets after prompt radiation doses. This information can provide insight on when thrombocytopenia occurs and when casualties would need platelet transfusions. The kinetics profiles can also be used to understand when casualties would be at risk of hemorrhage. This information also provides input into a physiologically based mortality risk prediction. Finally, the models illustrate the timeframe in which the casualty 
would be expected to recover. An example of this output comparing 3 Gy and 5 Gy FIA exposures is provided in Figure 5.

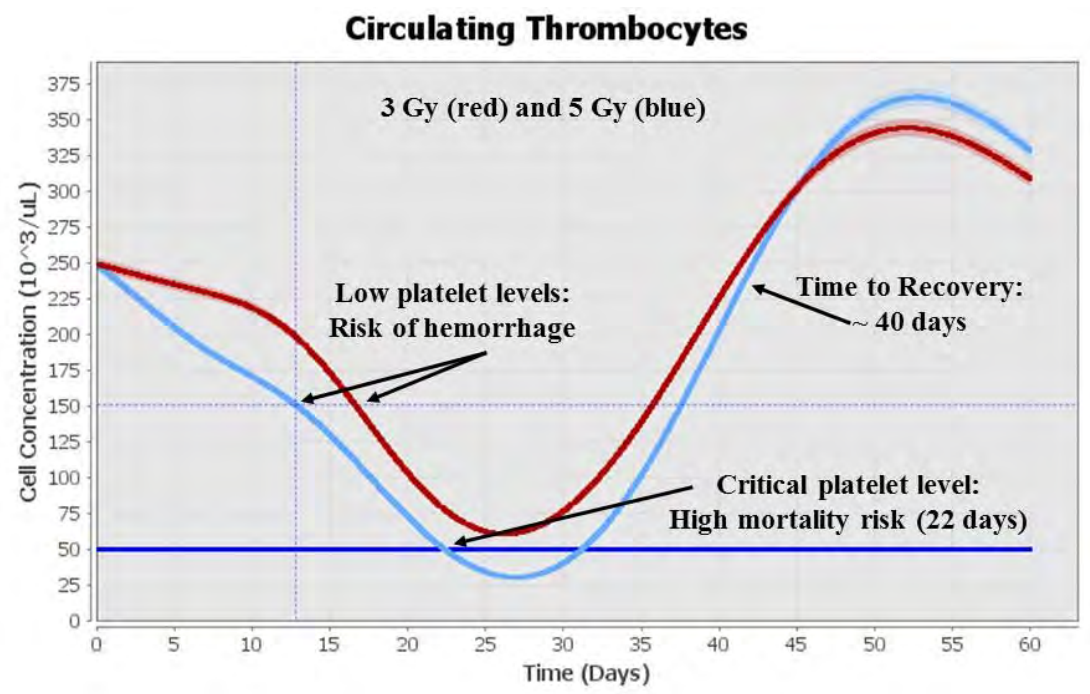

Figure 5. Predicted platelet levels after prompt radiation exposure.

\subsubsection{Granulopoiesis Model}

Granulopoiesis is the process by which mature granulocytes are generated from pluripotent HSCs. Granulocytes are a type of leukocyte and can be subdivided into neutrophils, eosinophils, and basophils. Neutrophils account for the majority of granulocytes and are involved in phagocytosis, the release of soluble anti-microbials, and generating neutrophil extracellular traps (NETs). The granulopoiesis model has four compartments: mitotic precursors in the bone marrow, post-mitotic precursors in the bone marrow, granulocytes in circulation, and granulocytes in the tissues.

All cells in the granulopoietic lineage are radiosensitive. The mitotic cells in the bone marrow are the most radiosensitive and become either damaged or weakly damaged. The cells in the other three compartments are less radiosensitive than mitotic cells and enter a single damaged state following radiation exposure. The weakly damaged cell compartment is used to model the late transient increase in granulocyte counts observed following radiation exposure (Bond 1965).

In Figure 6, we compare the model output (black line with shaded area showing model variability) with case study data (black dots) for an exposure of 2.7 Gy. This case shows the characteristic

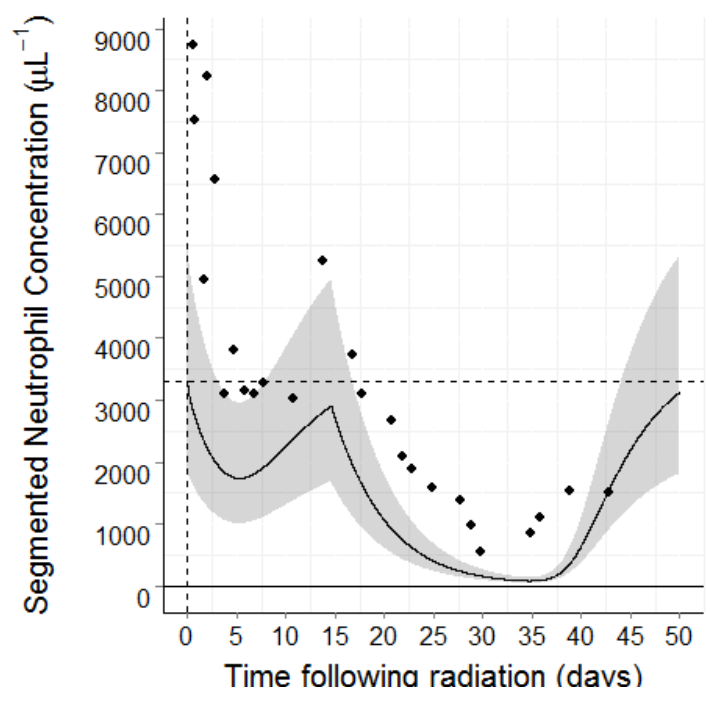

Figure 6. Predicted neutrophil concentrations overlaid on 2.7 Gy case study data. 
abortive rise that occurs with neutrophils after about two weeks.

\subsubsection{Lymphopoiesis Model}

Lymphopoiesis is the process by which lymphocytes are generated from the bone marrow. The three main types of lymphocytes are T cells, B cells, and natural killer (NK) cells. B and NK cells mature in the bone marrow, while $\mathrm{T}$ cell progenitors migrate to the thymus for maturation. Once mature, cells enter the circulation and peripheral lymphoid organs, including the spleen and lymph nodes.

The human lymphopoiesis model consists of three compartments: mitotic precursors in the bone marrow, post-mitotic precursors in the bone marrow or thymus, and lymphocytes in circulation. All cells in the lymphopoiesis model are considered radiosensitive and, once damaged, decay at a specific rate. The characteristic features of lymphocyte dynamics after radiation exposure is the dose-dependent immediate decline of circulating lymphocytes, due to their high radiosensitivity. Lymphocyte levels remain low for an extended period of time before recovering. These features are illustrated in the simulations in Figure 7.

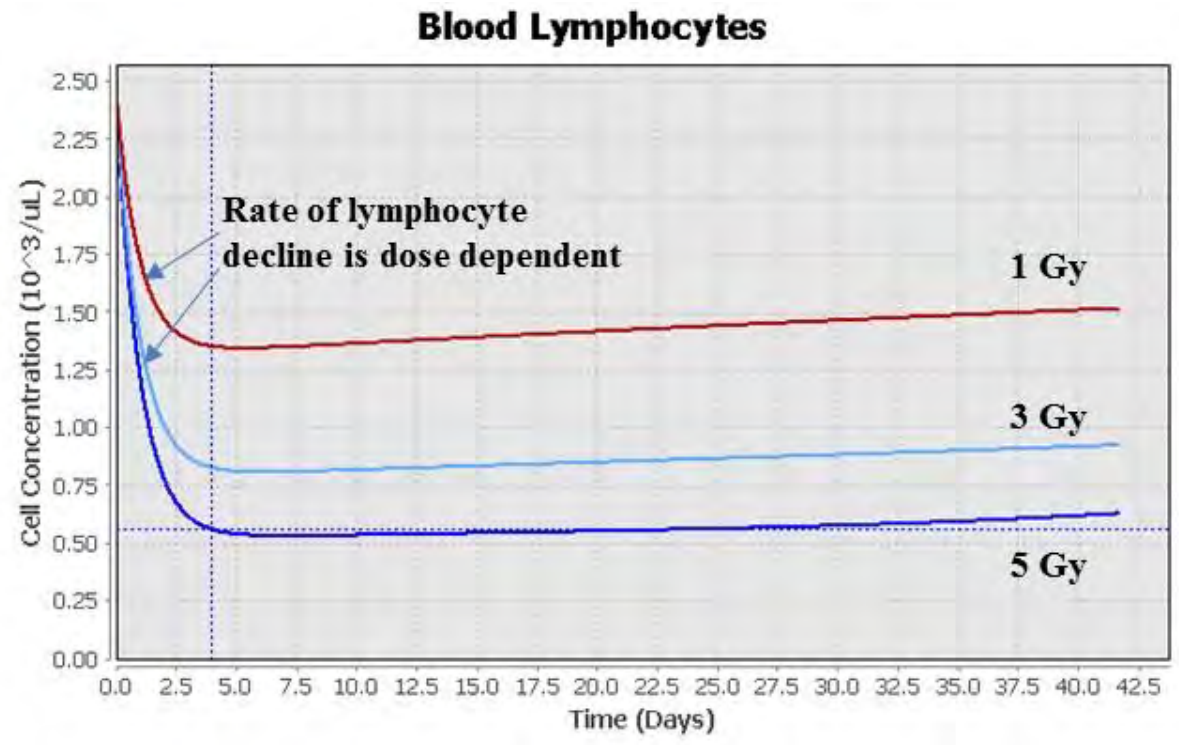

Figure 7. Simulated lymphocyte depletion after 1, 3, and 5 Gy radiation exposure.

\subsubsection{Small Intestine Model}

Lower gastrointestinal (GI) effects after acute radiation exposure include diarrhea, dehydration, and electrolyte imbalance (Dainiak 2011). Although effects in the lower GI system are observed in the prodromal, latent, and manifest phases of acute radiation syndrome (ARS), each phase is thought to be attributed to different pathophysiological mechanisms (Anno 1991). Survival times of animals following high radiation doses suggest that it is the second phase of GI distress that should be studied to help understand mortality. Following high dose irradiation in mice, death occurs 4 to 8 days after exposure (Booth 2012a, Booth 2012b). In rhesus macaques, the survival time following high radiation doses ranges between 3 to 14 days. Therefore, the current 
focus of our work is on modeling the latent phase of GI distress to adequately understand mortality during this timeframe and any increased morality from additional injuries, such as burns.

N.B. Although RIPD currently has a model that sufficiently estimates prodromal GI effects, a known limitation with the RIPD/HENRE is the lack of estimation of the manifest phase of GI syndrome. In this phase, the occurrence of diarrhea symptoms is observed in patients after 4-5 weeks post-exposure of radiation doses greater than $3 \mathrm{~Gy}$.

The current physiological model in RIPD that estimates latent phase lower GI effects, referred to as the gut injury model, was based on small intestine epithelia (Anno 1991). The model assumes that a reduction in the number of epithelial cells after radiation exposure was the dominant physiological change leading to lower GI distress in the latent phase. However, this model is more complicated than the model published by Smirnova (2010). Simplicity becomes very important when data is not available to support more complicated model approaches, especially when developing human parameters for models developed from animal experiments, since much less data is available in humans. Also, the current model in RIPD does not account for mediator feedback in the dynamics modeled; however, this is the main mechanism of action in the GI system for other acute injuries, such as burn. Therefore, we explored the simplified models developed by Smirnova for further model development and, in particular, for integrating combined effects of burn injury going forward.

\subsubsection{Morphology and physiology}

The small intestine is structurally divided into three parts: the duodenum, the jejunum, and the ileum (Barrett 2010). The duodenum is the first section of the small intestine and is continuous with the stomach. The point of connection between the duodenum and the jejunum marks the transition from the upper to the lower GI tract. The jejunum is the midsection of the small intestine, and the ileum is the final section. The epithelial surface of the small intestine separates the lumen (i.e., space where food passes) from the submucosa. 


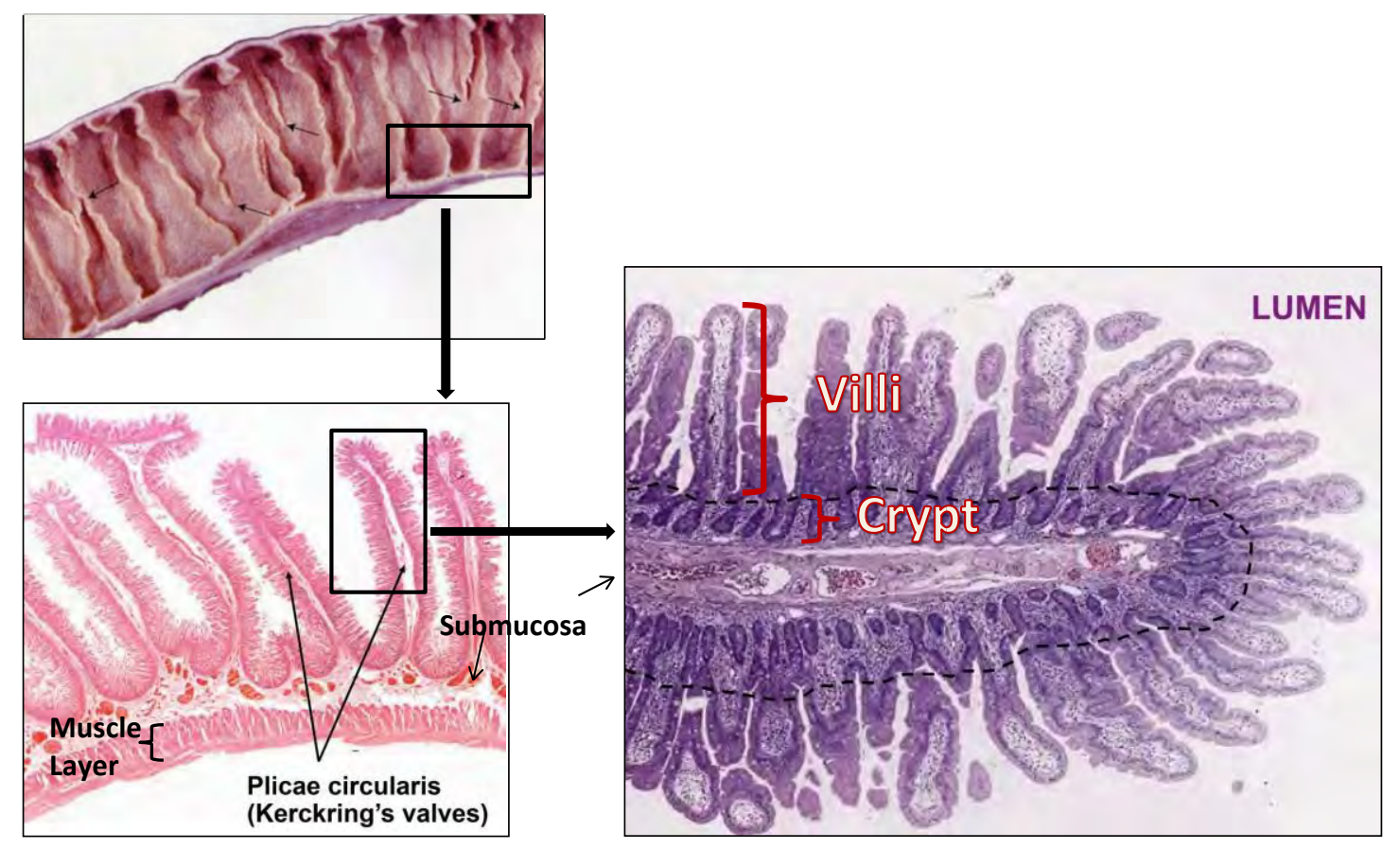

Figure 8. Morphology of the small intestine epithelium (adapted from Velkey 2009).

Figure 8 shows the morphology of the small intestine at multiple resolutions. At the highest level, a fold in the epithelium is known as a plicae circularis. Each plicae circularis contains many finger-like projections known as villi. The epithelial layer is highly convoluted, increasing the surface area available for absorption and slowing the passage of food. Each villus is surrounded by crypts, which contain progenitor and stem cells. As cells become differentiated and mature, they travel up from the base of the crypts and onto the villi.

The villus epithelium is responsible for the absorption of nutrients and serves as a barrier. The crypt epithelium is responsible for proliferation and cell renewal (Barker 2007). Two functionally distinct stem cell populations reside at the bottom of the crypts and, through a series of differentiations, are capable of producing all the cells that line the intestinal epithelium. As cells mature, they migrate up the crypt and onto the villi. Once cells are approximately two thirds up the crypt, they become non-mitotic and continue to mature as they travel up the remainder of the crypt and onto the villus. Cells eventually reach the tip of the villus, where they are sloughed off into the lumen.

For modeling purposes, the two stem cell compartments' cells are all grouped into one compartment, representing crypt proliferation. Non-mitotic cells in the upper portion of the crypt are in the crypt maturation compartment. All cells on the villus are in the villus compartment.

\subsubsection{Model structure}

The model developed by Smirnova predicts epithelial and progenitor cell dynamics within the small intestine of rodents (Smirnova 2010). We have used this model as a starting point in our 
work (Wentz 2015b), however, the sources of many parameter values from Smirnova's model were not available. Therefore, we collected murine data on normal state parameters and radiation effects and then updated and documented the model parameters. We then collected as much human data as was available to derive human values for as many parameters as possible, to simulate GI cellular dynamics in humans (Wentz 2015c).

The mathematical model has three compartments: proliferative cells in the crypts, maturing cells in the crypts, and enterocytes on the villus (Smirnova 2010) as shown in Figure 9.



Figure 9. Conceptual model of small intestinal cell dynamics.

Data collected for this work included data to support normal state compartmental transit rates, repopulation rate of the mitotic cells, and the concentration of cells in the crypt proliferation compartment, the crypt maturation compartment, and the villus compartment. Since cellular dynamics are not the same in different regions of the small intestine (Wright 1982), we focus on the jejunum due to the sufficient availability of data in this region. Some of the parameters derived for the human steady state are listed in Table 6:

Table 6. Derived steady-state kinetic parameters for the jejunum in humans.

\begin{tabular}{lc}
\hline Parameter & Derived Value \\
\hline $\begin{array}{l}\text { Steady-state rate of proliferative } \\
\text { compartment repopulation }\end{array}$ & $0.24 \mathrm{~d}^{-1}$ \\
$\begin{array}{l}\text { Maturation rate through proliferative } \\
\text { compartment }\end{array}$ & $0.24 \mathrm{~d}^{-1}$ \\
$\begin{array}{l}\text { Maturation rate through maturation } \\
\text { compartment at equilibrium }\end{array}$ & $1.09 \mathrm{~d}^{-1}$ \\
$\begin{array}{l}\text { Maturation rate through the villus at } \\
\text { equilibrium }\end{array}$ & $0.47 \mathrm{~d}^{-1}$ \\
\hline
\end{tabular}

For complete model details, parameter values, data, and references, see Wentz 2015c. 


\subsubsection{Radiation effects}

The latent phase of GI syndrome, involving diarrhea, is caused by a radiation induced breakdown of the intestinal epithelial lining. Radiation leads to the early death of proliferating crypt cells. The 2-4 day delay between radiation exposure and the observed clinical effects is representative of the needed time for crypt cell maturation and migration to the villus. Besides diarrhea, the breakdown of the epithelial lining leads to dehydration and electrolyte imbalance (Dainiak 2011). Furthermore, the loss of epithelial cell layer integrity permits bacterial translocation from the intestinal lumen into the bloodstream during an immunocompromised state which is in part due to the radiation effects on the hematopoietic system (Li 2013).

The mechanisms of pathophysiology in the small intestine, following radiation exposure, have been elucidated through studies in rodents. Morphological changes from radiation-induced death of crypt cells include reduced numbers and depth of crypts and collapsed villi after 2-3 days (Withers 1971, Wiernik 1962). While crypts rapidly undergo apoptosis, cells in the villi demonstrate some radioresistance.

With any survival of stem cells, the crypts will regenerate within 3 to 4 days post-irradiation and the villi architecture will regenerate within 6 to 8 days (Umar 2010). If entire crypts are destroyed, surviving crypts can undergo fission to increase the total number of crypts (Cairnie 1975). However, if surviving crypts are too low to restore the epithelial barrier ( $>4 \%)$, the GI damage will lead to onset of diarrhea, dehydration, and mortality (Booth 2012a).

For modeling purposes, dose response of crypt cells in the proliferation compartment to radiation damage is needed. The rate at which damaged cells die and contribute to feedback mechanisms are also needed.

Rodent parameters were derived for the model from available data (Wentz 2015c); however, little human data was identified for parameterizing the model for human response. Therefore, we used murine values as a default for several parameters. Though, the dose response was derived from human data that quantified the epithelium surface length and crypt mitoses during and after multi-dose radiation therapy (Trier 1966). The resulting radiation parameters for the model are listed in Table 7.

Table 7. Derived radiation parameters for the jejunum in mice and humans.

\begin{tabular}{lcc}
\hline Parameter & $\begin{array}{c}\text { Derived Value } \\
\text { (Murine) }\end{array}$ & $\begin{array}{c}\text { Derive Value } \\
\text { (Human) }\end{array}$ \\
\hline $\begin{array}{l}\text { Determines dose response } \\
\begin{array}{l}\text { Extrapolation number for dose- } \\
\text { response curve }\end{array}\end{array}$ & $3.1 \mathrm{~Gy}$ & $2.5 \mathrm{~Gy}$ \\
$\begin{array}{l}\text { Rate of damaged cell death } \\
\begin{array}{l}\text { Relative effect of damaged cells on } \\
\text { repopulation rate }\end{array}\end{array}$ & $1 \mathrm{~d}-1$ & 3 \\
\hline
\end{tabular}

We compared the data from the Trier study to the model prediction using the same radiation dose regimen as shown in Figure 10. 


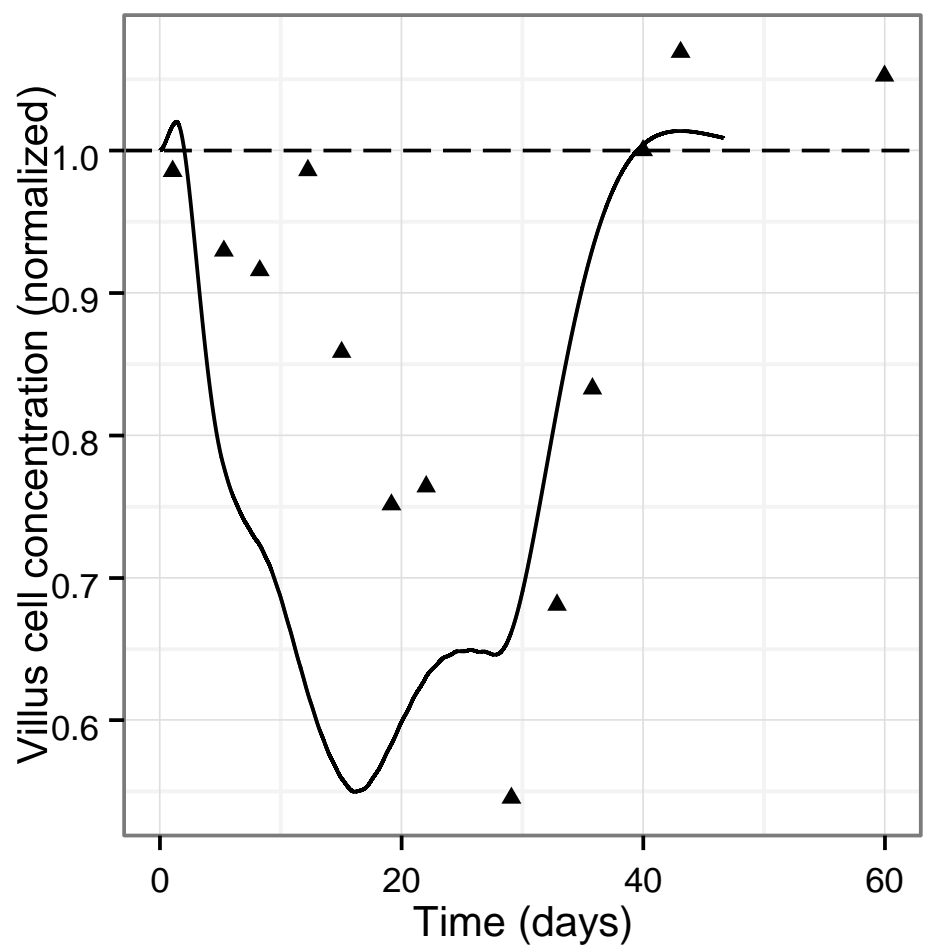

Figure 10. Comparison of human model predictions with data from Trier 1966.

Although the nadir of the model is comparable to the nadir of the data, the model predicts the nadir much earlier than observed in the human data. The difference might be attributed to uncertainties in translating the data for comparison and the dose protraction used in the case study. However, refinements to the model are justified if additional radiosensitive human data can be identified.

\subsection{Modeling Combined Injury}

Casualties of radiological or nuclear event scenarios will likely experience exposures to radiation in combination with other injuries, such as burn and trauma. Morbidity is accelerated in combined injuries, the magnitude of response is greater, and increased mortality is observed. The processes leading to these observations are complex. Recent research efforts have provided valuable insight into the underlying pathogenesis of combined injury, and major strides have been made in understanding processes common to radiation and traumatic injuries, such as sepsis, inflammation, immune dysfunction, and repair mechanisms. Therefore, one of the main objectives with the development of HENRE using physiological models was to improve current casualty prediction tools by developing a physiologically-based model of combined injury, beginning with radiation and burn. The current mechanistic knowledge of radiation, burn, and radiation combined injury was previously reviewed (Stricklin 2010a, Stricklin 2010b) and potential areas of interaction between radiation and burn injury were identified.

The complexity of the pathophysiology, involving multiple interconnected cellular and molecular pathways and cascades of events, presents challenges for developing a mathematical 
model of combined injury based on mechanisms. Understanding the consequences of radiation exposure and traumatic injuries requires a systems biology approach that addresses changes at the molecular, cellular, tissue, organ, and organism levels. Limitations in the available data present additional challenges. To model such a complicated system, we have simplified the problem by adopting idealizations and approximations that preserve the essential features of the system (Lin 1974).

N.B. The current effort which has manifested in HENRE 2.0 addresses only radiation and burn combined injury. The progress achieved to date with modeling radiation and burn combined pathophysiology, which includes early microvascular changes and hematopoietic effects. The impacts of combined radiation and thermal injury on the GI system are impacted by the limited availability of data from the burn community for the GI system. As data becomes available, models will be updated and integrated in future iterations of HENRE. Furthermore, other types of combined traumatic injuries will be included in the future.

\subsubsection{Modeling Boundaries}

The emphasis in our combined injury modeling aims was to predict the increased risk of lethality and other clinical outcomes resulting from the combination of injuries. Therefore, the focus of our modeling was on understanding and modeling injury mechanisms that are in the potentially survivable range. Generally, lethal insults are predicted in HENRE by traditional dose-response curves, usually in the form of probit models. However, physiological modeling aids in understanding the increased risk of lethality, where potentially survivable insults are present in combination. In some cases, the physiological modeling also helps to delineate the time course of injury, providing valuable information on time-dependent mortality and injury. The initial modeling efforts have also been placed on injuries that receive no specialized medical care. The potentially survivable dose range for the modeling effort was estimated by SMEs to be 6-8 Gy FIA gamma radiation doses and 30-35\% TBSA of burn injury (Stricklin 2010b).

\subsubsection{Modeling the Pathophysiology}

Modeling of pathophysiological processes were prioritized by a) their ability to drive mortality, b) processes that likely lead to synergistic effects, c) time scale of evolution (processes which lead to mortality in order of occurrence), and d) availability of data.

For burn and radiation, fluid loss, fluid shifts, and cell loss leading to shock are the most immediate drivers for mortality and were the initial focus of combined injury modeling. Processes that are thought to interact synergistically are inflammation, permeability changes, and infection; all of these processes are influenced by cell loss and are interconnected. For example, inflammatory mediators can impact the GI tract and cause permeability changes that, in turn, lead to translocation of bacteria into the systemic circulation. Both cell loss and inflammation can lead to a compromised immunological state and the inability to handle infection. Collectively, these effects result in greatly increased risk of sepsis.

Based on discussions by a panel of SMEs, the organ systems and processes thought to play a critical role in radiation and burn combined injury were identified and organized according to the illustration in Figure 11 (Stricklin 2010b). 


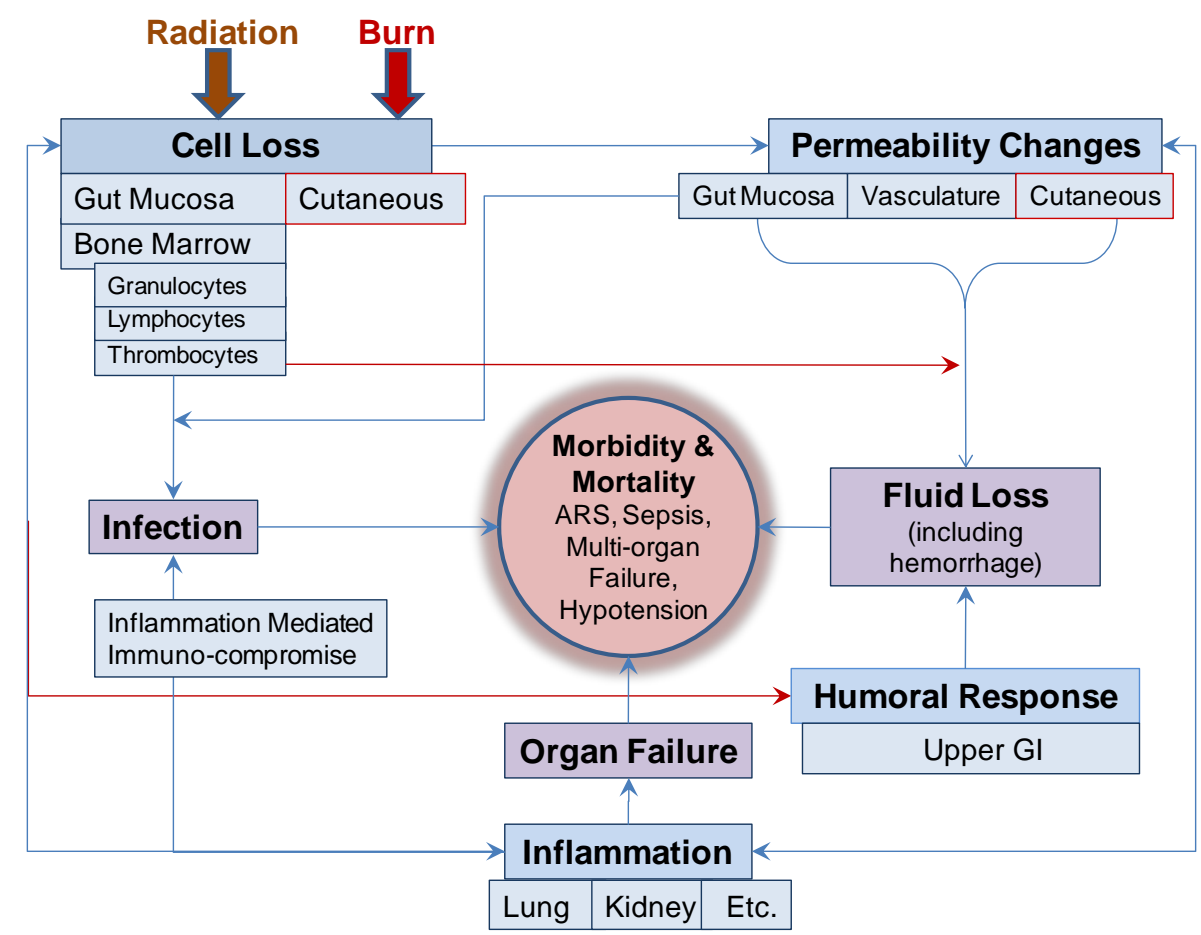

Figure 11. Interaction of pathophysiological processes in combined injury.

The pathophysiological processes occur in multiple organ systems with different rates and timescales. Organs and systems that show effects earliest were focused on first, including skin, hematopoietic, GI and vasculature systems. Delayed effects in combined injury are expected to have an earlier onset and occur at lower doses/insult severities, these processes will be addressed later.

The processes and organ systems addressed to date in combined radiation and burn injury are listed in order of priority in Table 8. Pathophysiological processes are common to more than one organ or system. For example, inflammatory processes impact all of the organs systems listed.

Table 8. Organs/systems and pathophysiological processes of concern in combined injury.

\begin{tabular}{ccc}
\hline Organs/Systems & Pathophysiological Processes & Outcome Risk \\
\hline \hline Skin/Vascular System & $\begin{array}{r}\text { Fluid loss, permeability } \\
\text { changes, cell loss }\end{array}$ & Circulatory shock \\
Hematopoietic System & Cell loss, leading to infection & $\begin{array}{c}\text { Hemorrhage, sepsis, } \\
\text { anemia }\end{array}$ \\
GI System & $\begin{array}{c}\text { Cell loss, permeability changes, } \\
\text { infection, and inflammation }\end{array}$ & $\begin{array}{c}\text { Hemorrhage, fluid loss, } \\
\text { sepsis }\end{array}$ \\
\hline
\end{tabular}

\footnotetext{
${ }^{2}$ Currently, red blood cell kinetics have not been included in the models for radiation and burn combined injury due to limitations of data.
} 
The pathophysiological processes listed in Table 8 can manifest in increased risk to the outcomes described in Figure 12. Burn injuries that cover $20 \%$ or more of the body can cause dramatic fluid shifts that result in risk of circulatory shock and compartmental syndrome which manifest and resolve with the first 48 hours after injury (Latenser 2009). Today, this phenomena is effectively treated with specialized fluid resuscitation regimes. Therefore, in patients that survive the risk of circulatory shock, respiratory distress, due to pulmonary edema, and renal distress, due to very high levels of amino acids and proteins from localized damage, can be observed. While radiation can impact all three of these burn related mechanisms, we only model the mechanisms leading to risk of circulatory shock. For now, respiratory and renal distress are not modeled since these patients would not manifest in the case of non-treatment. However, it is important to keep these mechanisms in mind as we begin to integrate treatment into the models.

The next mechanisms under consideration are driven by the radiation insult. GI effects can manifest over at higher radiation doses after one to two weeks. Loss of intestinal crypt cells by direct cell killing and inflammatory related permeability changes work in concert to compromise the integrity of the GI system. Similarly, radiation-induced loss of hematopoietic blood cells result in extended periods of neutropenia, lymphopenia, and thrombocytopenia. If stem cells are depleted from radiation cell killing, hematopoietic failure will result and blood cell levels will not recover. Burn may exacerbate these radiation effects through the systemic inflammatory and hyper-metabolic states that occur after significant thermal injury.

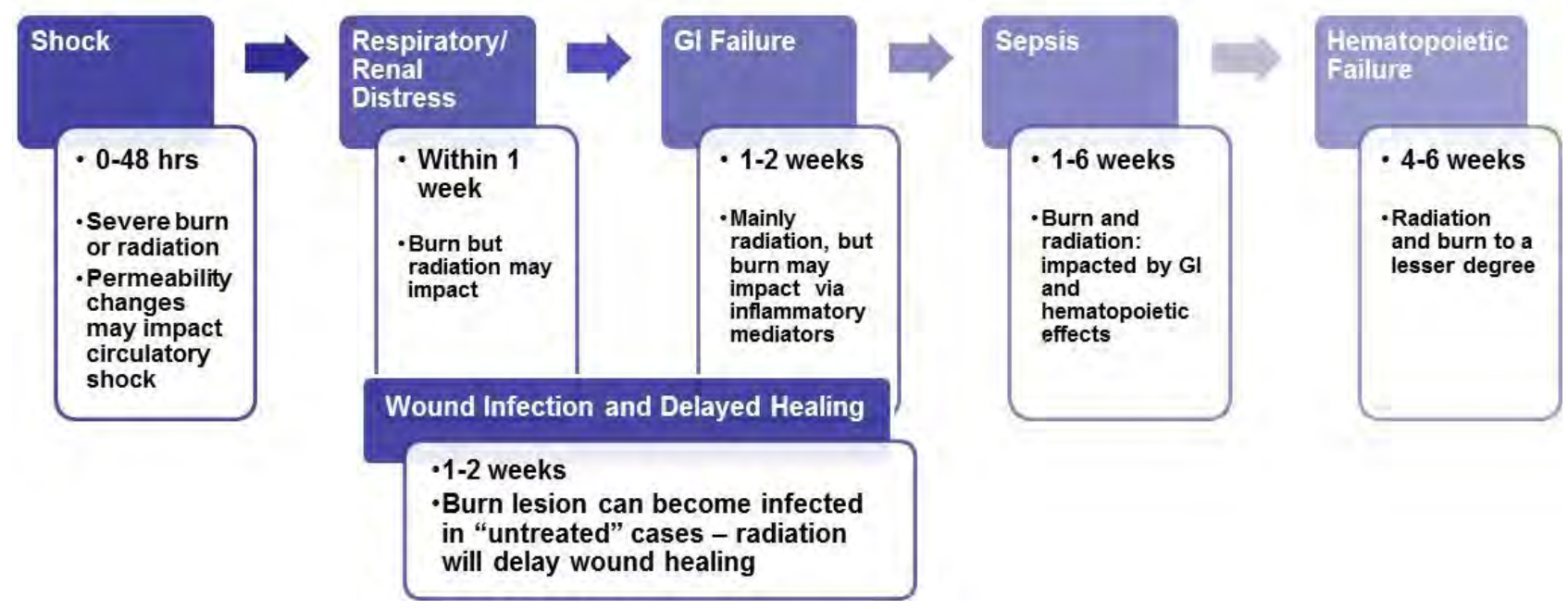

Figure 12. Timeline of effects from thermal and radiation injury.

As mentioned previously, the priority of the current modeling effort was based on the timeframe in which mechanisms occur and for which sufficient data exists. Therefore, for combined injury modeling, circulatory shock, as driven by thermal injury, was modeled first and then radiation effects were integrated. The next mechanism for increased mortality has underpinnings in the GI system. However, due the lack of data on burn effects, integration of burn into the available GI models for radiation injury was not developed for this version of HENRE. Recent and ongoing experimental research will enable this integration in the near future. As described previously, hematopoietic models of radiation effects were recently updated and sufficient data on burn made it possible to integrate burn effects into those models. Figure 13 illustrates the series of 
physiological models in HENRE addressing radiation and burn combined injury. The circulatory shock and hematopoietic models are completed; work on the GI model is ongoing.

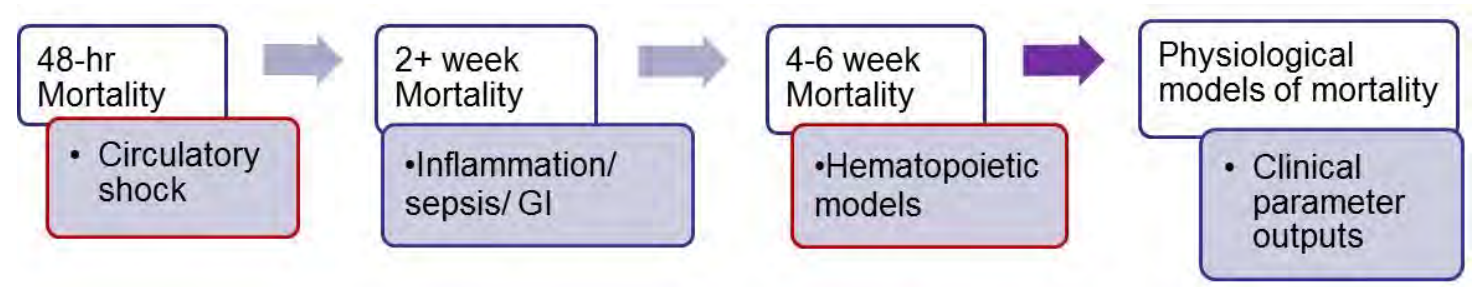

Figure 13. Combined radiation and burn models for HENRE (in progress or completed).

\subsection{Risk of Circulatory Shock Estimation}

Thermal injury causes a series of interrelated events within a short period time, resulting in a risk of burn shock (Latenser 2009, Williams 2009). Burn shock is a combination of several circulatory abnormalities which include distributive shock, hypovolemic shock, and cardiogenic shock (Shaw 1994). Circulating blood volume lost to the interstitial space leads to hypovolemia, which can occur with burn injuries involving 15\% TBSA or more. Edema, which plays a critical role in the pathophysiological process of burn shock, begins immediately after injury and resolves after about 48 hours. Edema refers to the accumulation of fluid in the interstitial space of tissues, which contributes to the loss of circulating fluid volume and increased pressure in the affected tissues. Edema can be observed even at sites distant from the burned area in cases of about $20 \%$ TBSA or more, due to underlying systemic mediator-related mechanisms. Although edema is a natural process in wound healing, it can cause complications after injury if it impairs tissue perfusion. In the affected area, the dramatic increase in interstitial fluid volume and increased pressures lead to damage of the interstitial structure due to denaturation and unraveling of connective tissue collagen fibers. Intra-vasculature fluid loss contributes to evolution of shock.

Furthermore, the microcirculation in the injured area loses its vessel wall integrity. Proteins are lost into the interstitial space, which causes the intravascular colloid osmotic pressure to dramatically drop. Fluid is further released from the circulation and a transient decrease in interstitial pressure results from the release of osmotically active particles. This process creates a suction which pulls fluid from the plasma space. A dramatic fluid flux into the interstitial space collectively results from decreased interstitial pressures, increased capillary permeability that results from circulating mediators, and an imbalance in hydrostatic and oncotic pressures. Fluid, electrolytes, and proteins then equilibrate between the intravascular and interstitial space (Latenser 2009, Williams 2009).

Although a number of additional mechanisms come into play to result in the increase risk of circulatory shock (Pham 2008), we identified the early permeability changes and fluid shifts resulting from thermal and radiation as key mechanisms for our modeling purposes (Stricklin 2013d). 


\subsubsection{Microvascular Exchange System (MVES) Model for Thermal Injury}

Several models of microvasculature exchange have been developed to understand the changes that occur after thermal injury, which result in dramatic fluid shifts that lead to burn shock (Artuson 1984, Hedlund 1988, Gómez-Cía 1993, Roa 1993, Ampratwum 1995, and Bert 1997). These models were developed to aid in the development of optimal fluid resuscitation regimes for treating burn patients. These efforts were successful and today burn shock can be completely alleviated with advanced colloid formulations.

The microvascular exchange model developed by Ampratwum in the 1990s was reasonably welldocumented in the literature, had been validated against burn patient data, and was not exceedingly complex. Therefore, we chose this model for estimating fluid shifts after thermal injury and for integrating radiation effects for estimating combined injury.

The microvascular exchange model describes the redistribution of fluid and albumin between three compartments: the circulation and the injured interstitial tissue, and the uninjured interstitial tissue as shown in Figure 14. The exchange of transcapillary fluid and albumin is modeled according to the coupled Starling equation, and the effect of burn is described by timedependent perturbations to the normal system dynamics. The main perturbations include fluid filtration coefficients, relaxation coefficient (decay of the perturbations), and exudation factor (protein concentration in exudate).

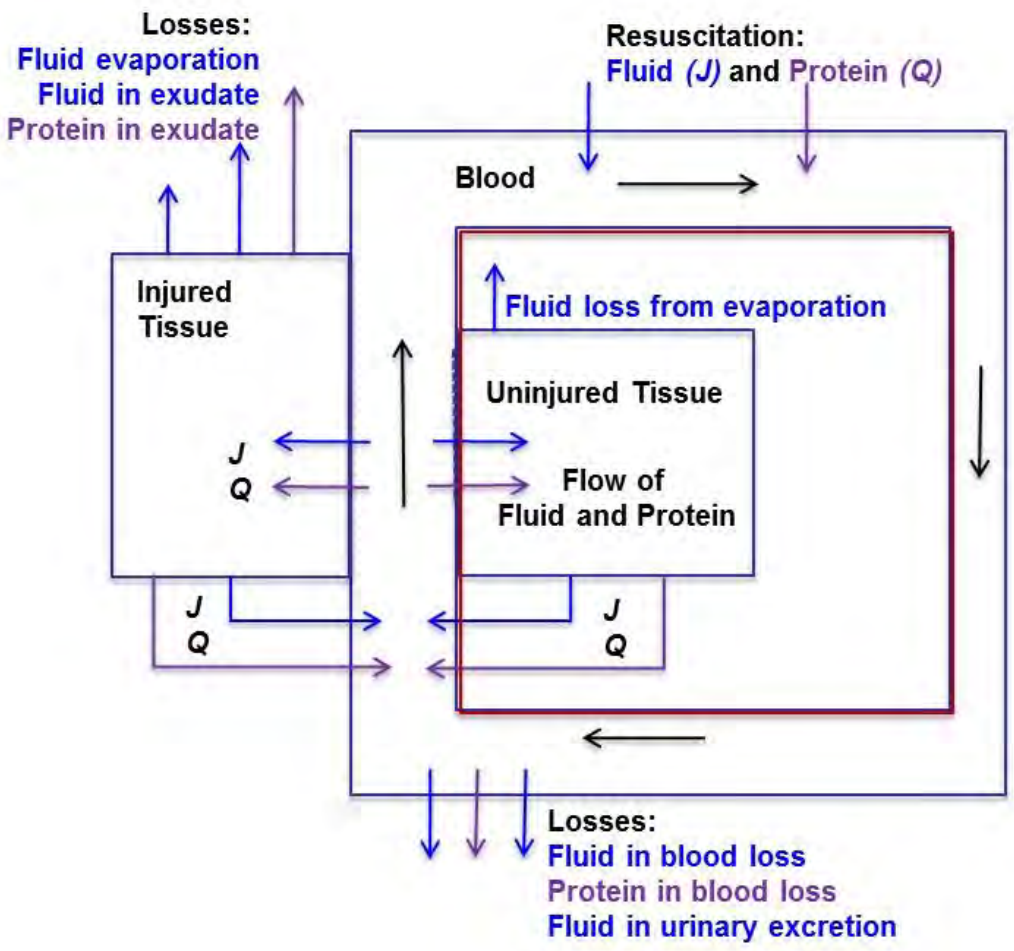

Figure 14. Compartment model of microvascular exchange for Burn Injury (Ampratwum 1995).

The MVES model has been implemented in HENRE and estimates the following parameters as a function of \% TBSA and fluid resuscitation, if applicable: 
- Albumin concentrations

- Albumin content

- Albumin transport rate

- Colloid osmotic pressure

- Filtration coefficient

- Fluid flux

- Fluid volumes

- Hydrostatic pressure

- Membrane permeability

- Reflection coefficient

Since we currently assume no advance care, advance fluid resuscitation is not included.

However, maintenance fluids (to off-set standard losses through evaporation and excretion) are included as a default. If a user wanted to simulate an instance where drinking water was not available for 24 to 48 hours after injury, an option to remove maintenance fluids is available.

\subsubsection{Integration of Radiation Permeability Changes}

\subsubsection{Summary of Radiation-Induced Permeability Changes}

A number of experiments studied the effects of radiation on the microvasculature of various tissues (Brooks 1956, Willoughby 1960, Mount 1964, Song 1966, Harris 1968, Eassa 1973, Ullrich 1977, Evans 1986, Krishnan 1988, Panes 1995, Waters 1996, and Gabrys 2007). The endpoints examined in these studies were variable since experimental design and analytical approaches evolved over the years. To examine the data collectively, the observed measurements were converted into relative permeability changes (Stricklin 2013b). Figure 15 summarizes the data collected in this work in terms of relative permeability changes as a function of radiation dose. The data was compiled for any endpoint (such as albumin or other protein leakage from the vasculature) that relates to changes in permeability within the first 48 hours after radiation exposure. Therefore, the data represents responses observed at a variety of different time points within the early phase after irradiation. The time-dependent response of increases in permeability is also important to understand, i.e. the rate of increase and the time for it to return to normal. However, there was not enough detail in the data to provide any consistent and useful information. The data indicates only modest changes in vascular permeability after radiation, as compared to burn. The relative changes in permeability after irradiation in different species and tissues ranged from 1.2 to 4.2 for radiation doses ranging from 1 to $80 \mathrm{~Gy}$ in the first 48 hours, with large variances among the different experimental data examined. 


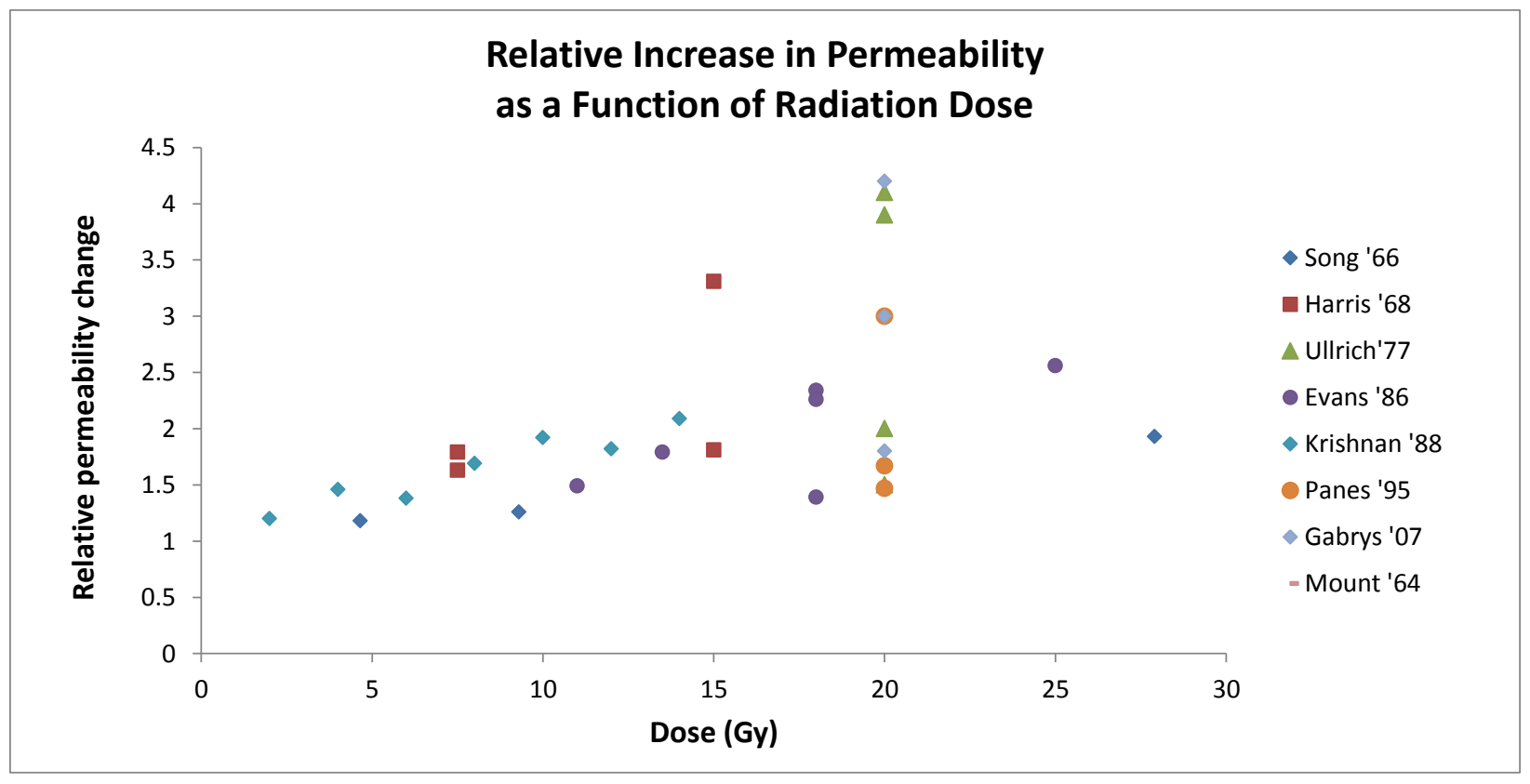

Figure 15. Summary of relative permeability changes observed in experimental studies as a function of radiation dose.

The radiation dose-dependent relative increase in permeability from the composite set of data was mathematically interpreted using a polynomial fit:

$$
y=-0.001 D^{2}+0.092 D+1,
$$

where $y$ is the relative permeability change, and $D$ is the radiation dose in Gy. This function was used to develop dose-dependent radiation perturbation parameters for inclusion in the MVES model.

\subsubsection{Integration of Radiation Perturbations in the MVES}

The parameters in the MVES for which radiation perturbations could be estimated was limited by availability of data. Data on changes in fluid volumes, plasma volumes, albumin transport, fluid leakage, and protein accumulation were available for comparisons (Brooks 1956, Willoughby 1960, Mount 1964, Song 1966, Harris 1968, Eassa 1973, Ullrich 1977, Evans 1986, Krishnan 1988, Panes 1995, Waters 1996, and Gabrys 2007). Based on these data, radiationinduced perturbations were estimated for the following:

- $\quad$ Capillary to interstitial filtration coefficient

- Membrane permeability coefficient

- Capillary reflection coefficient for albumin

Only the radiation-induced changes occurring in the early phase after irradiation are described (up to 48 hours after irradiation) and the same mathematical form of burn-induced perturbations and relaxation is used. The general form of the burn-induced perturbations used in all of the functions described in the model is:

$$
1+G * e^{-r\left(t-t_{0}\right)},
$$


where $G$ is the perturbation of a specific parameter, $r$ is the relaxation coefficient which described the rate at which the perturbation returns to normal, and $t$ is the time elapsed after injury. Based on the observed resolution of fluid shifts in burn after about 48 hours, the model assumes a general relaxation rate in all cases to be 0.025 hour $^{-1}$.

To determine the values for radiation perturbation, a dose-dependent function of $G$ was back calculated by experimenting with values of $G$ in the MVES that would correspond with the expected relative permeability changes based on the dose-response relationship established above. Simulations using the MVES model were performed using different values of $G$ ranging from 0 to 10. Model outputs for albumin content in tissue were used in estimating the perturbation since this was a common metric in the experimental research. For each perturbation $(G)$ examined, the maximum albumin content increase in tissue for each simulation was identified and compared to baseline tissue albumin to determine the maximum relative change. The relative changes in permeability determined in the simulations using different values of $G$ were then compared to the expected dose-dependent permeability changes according to the doseresponse relationship of permeability change presented above. The simulated data are presented in Table 9 along with the value of $G$ which, when used in the MVES model, would provide the corresponding change in permeability. Based on this data, the dose-response relationship for the value of $G$ was determined with a polynomial fit resulting in the following dose-response function for the radiation perturbation parameter:

$$
G=0.0097 D^{4}-0.0575 D^{3}+0.1723 D^{2}-0.0098 D,
$$

where $G$ is the radiation perturbation parameter and $D$ is the dose in Gy.

Table 9. Predicted relative permeability changes according to radiation dose and the corresponding values of $\boldsymbol{G}$ for the MVES model.

\begin{tabular}{ccc}
\hline Dose (Gy) & $\begin{array}{c}\text { Predicted relative } \\
\text { permeability change }\end{array}$ & $\begin{array}{c}\text { Value of radiation } \\
\text { perturbation } G^{1}\end{array}$ \\
\hline \hline 0 & 1.00 & 0 \\
1.25 & 1.11 & 0.2 \\
2.15 & 1.19 & 0.4 \\
2.7 & 1.24 & 0.6 \\
3.1 & 1.28 & 0.8 \\
3.5 & 1.31 & 1 \\
4 & 1.35 & 1.5 \\
4.3 & 1.38 & 2 \\
4.9 & 1.43 & 3 \\
5.4 & 1.47 & 4 \\
5.7 & 1.49 & 5 \\
5.9 & 1.51 & 6 \\
\hline${ }^{1}$ Based on relative changes in simulated albumin content in tissue.
\end{tabular}


Using the radiation perturbation parameter, the MVES model was used to simulate expected impact of radiation on different outputs of the model, as shown in Figure 16.

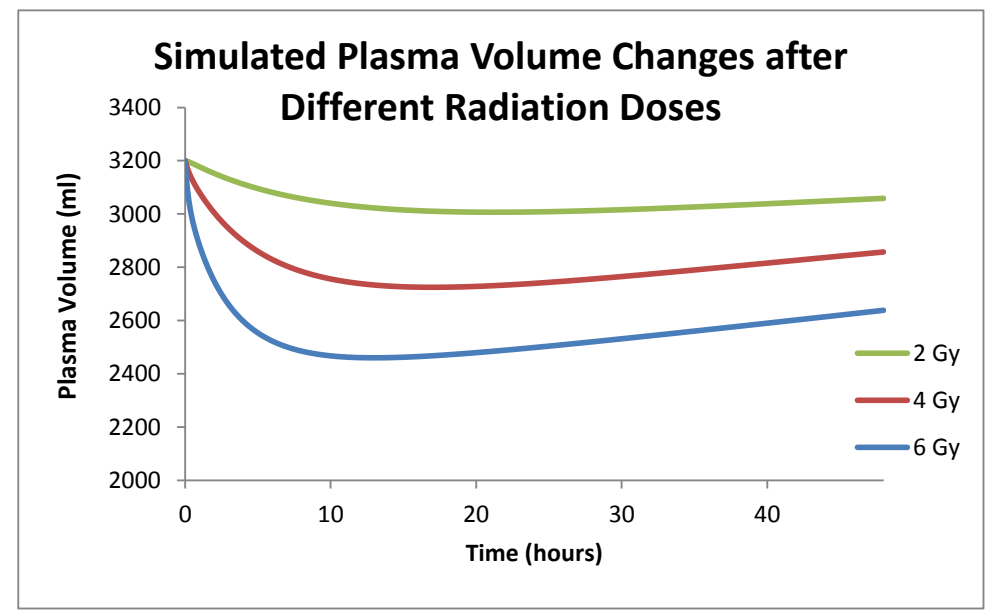

Figure 16. Simulated changes in fluid volume after different radiation doses.

Values of $G$ required to obtain expected changes in radiation permeability increase rapidly at higher radiation doses. Therefore, the mechanisms which are modeled in MVES may not be adequate to describe all of the relevant mechanistic changes that occur with high dose radiation exposures. The MVES model bases permeability changes largely on changes to the endothelial pore size and subsequent changes in osmotic pressure, which is determined by mechanisms such as mediator release after acute injury. Similar mechanisms are relevant to radiation exposure, however, radiation can also cause direct cell killing. Detectable changes have been observed in endothelial cells at 4 Gy (Rosen 1998). Therefore, at higher doses, the MVES model may not be able to adequately predict permeability changes and effects due to the impact of cell killing on the structural integrity of the vascular endothelium. Additional work is needed to evaluate the boundaries for which the current model is valid.

\subsubsection{Combined Injury Effects}

The MVES model, with radiation permeability changes, can be used to evaluate the impact of burn, radiation, or combined radiation and burn. As expected, simulated permeability changes by burn are increased when radiation is also used as an insult. The combined insults result in more profound fluid volume minimums, as illustrated in Figure 16, which then can be associated with increased mortality. 


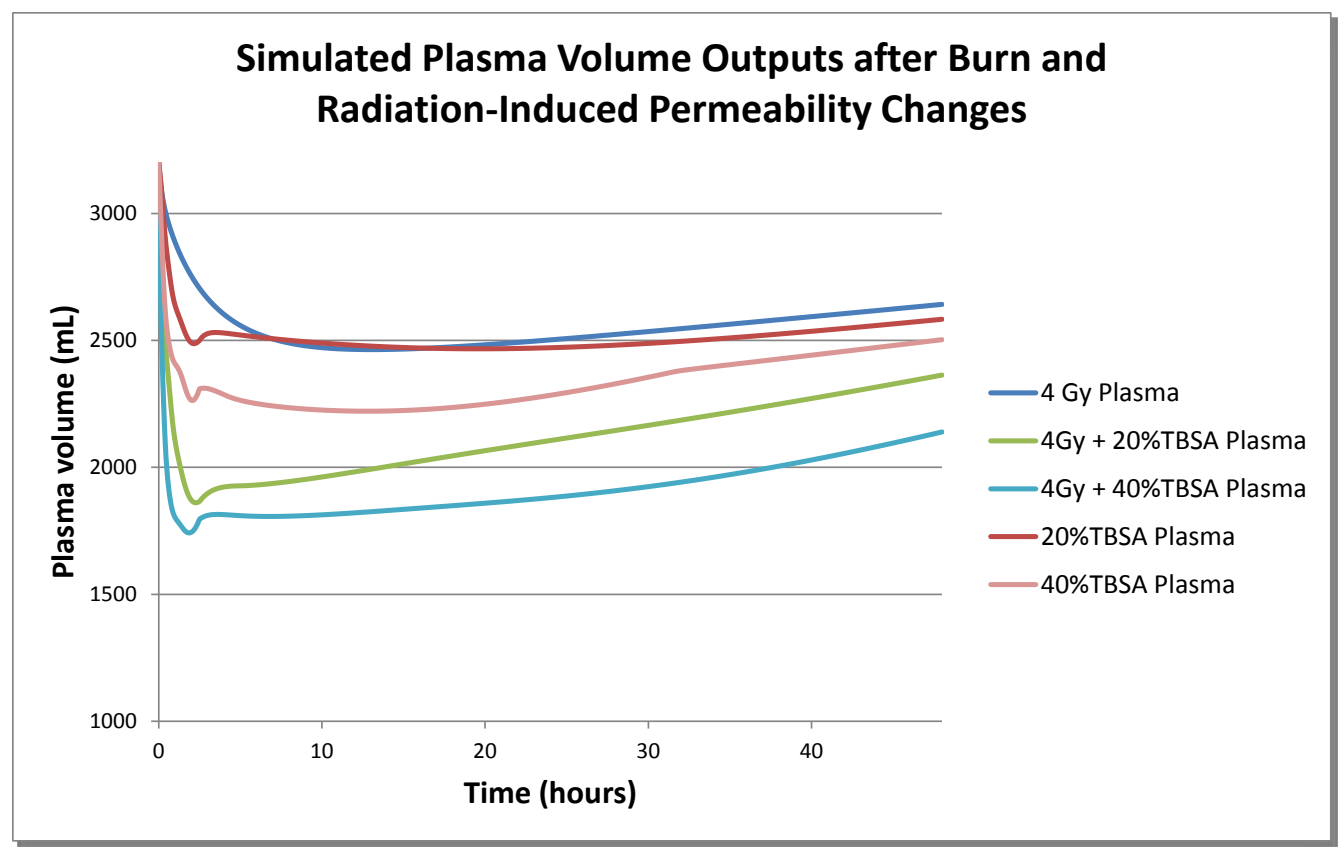

Figure 17. Simulated changes in plasma volume after radiation, burn, and combined injury.

\subsubsection{Risk Mapping for Circulatory Shock and 48-hour Mortality Risk}

The risk of circulatory shock after thermal injury is most prominent in the first 48 hours after injury (Latenser 2009). Circulatory shock is a critical condition resulting from circulatory failure and inadequate tissue perfusion (Leach 2004). With insufficient tissue perfusion, tissues can no longer meet metabolic requirements, cellular hypoxia occurs, and metabolic waste accumulates (Kelley 2005). The dramatic shift in fluids after thermal injury causes significant loss of plasma from the circulation, resulting in hypovolemia, and the phenomena referred to as burn shock (Shaw 1994). If plasma losses lead to the loss of about one fifth or more of the normal blood volume, hypovolemic shock will result.

Table 10 lists the percent of total blood volume loss associated with different severity levels for hypovolemic shock and the associated physiological responses (Tintinalli 2011). The equivalent of total plasma volume for each severity category (of blood volume loss) was calculated based on the initial conditions ( $3200 \mathrm{~mL}$ ) in the MVES model. Hypovolemia severity level 3 is relatively life-threatening, requiring fast intervention, and level 4 requires immediate intervention. 
Table 10. Hypovolemic shock severities.

\begin{tabular}{|c|c|c|c|}
\hline$\%$ Blood Loss & $\begin{array}{l}\text { MVES plasma } \\
\text { equivalent }(\mathrm{mL})\end{array}$ & $\begin{array}{l}\text { Severity of } \\
\text { shock }\end{array}$ & Response \\
\hline normal & 3200 & & \\
\hline$<15$ & 2752 & 1 & Compensated constriction of vascular bed \\
\hline $15-30$ & $2720-2240$ & 2 & $\begin{array}{l}\text { Decreased cardiac output, increased } \\
\text { respiratory rate }\end{array}$ \\
\hline $31-40$ & $2208-1920$ & 3 & $\begin{array}{l}\text { Systolic blood pressure drop, marked } \\
\text { tachycardia, altered mental status }\end{array}$ \\
\hline$>40$ & 1888 & 4 & $\begin{array}{l}\text { Extreme tachycardia, significantly } \\
\text { decreased blood pressure, and loss of } \\
\text { consciousness }\end{array}$ \\
\hline
\end{tabular}

To estimate the risk of circulatory shock, we associate plasma volume minimums, as predicted by the MVES model, with probability of mortality, established by a previously developed probit model for 48-hour untreated burn mortality (Stricklin 2012b). The relationship of the two is shown in Figure 18. The model predictions for plasma volume minimums and the time to the minimum correlate well with mortality and time to mortality. Mechanistically, reduced plasma volume can be directly associated with increased risk of shock and mortality. The correlation between plasma volume minimum and mortality should not be viewed as exact representations of what occurs in the first 48 hours after burn (and radiation), but rather overview of many complex effects that collectively lead to the estimated outcomes. If additional data or more precise estimates of effect become available, our modeling approach can be revised.

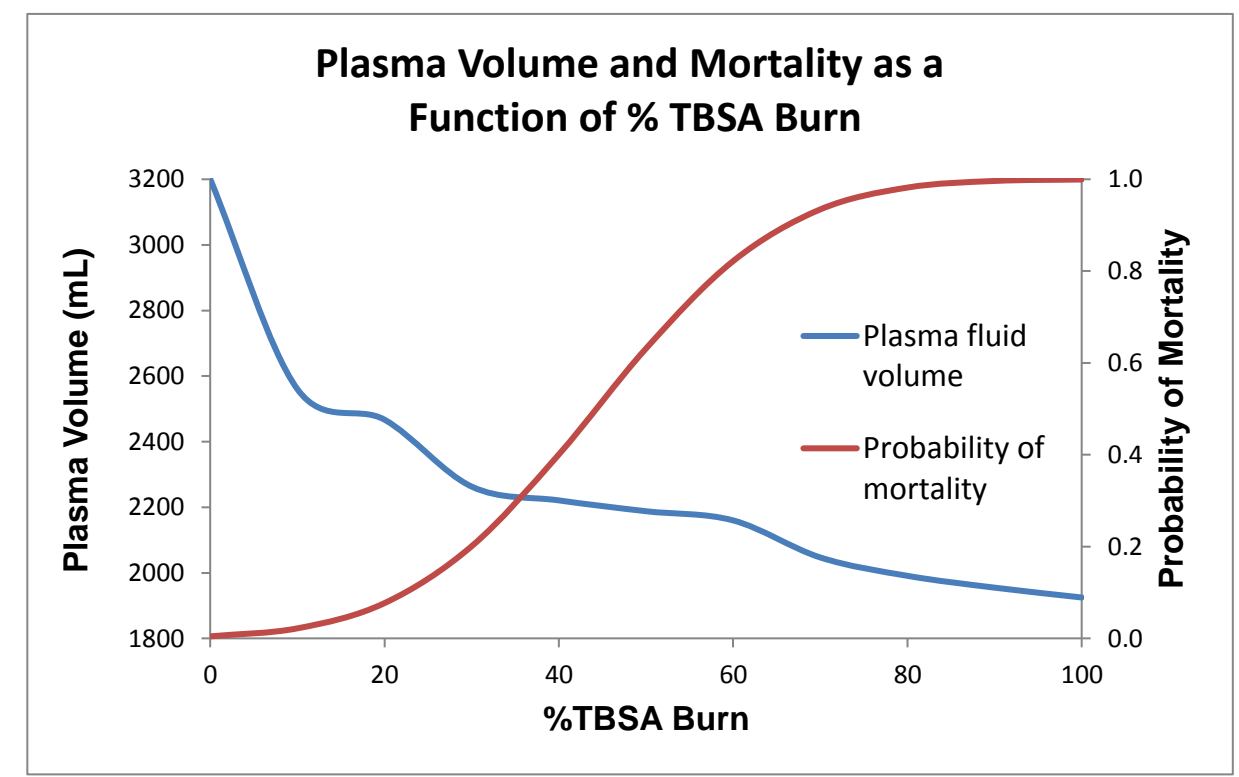

Figure 18. Simulated minimum plasma volumes and probability of mortality as a function of $\%$ TBSA. 
The simulated outputs of fluid volume minimums for different levels of burn (in \% TBSA) were mapped to the probability of mortality in the first 48 hours for different $\%$ TBSA based on a 48hour untreated burn mortality probit (Stricklin 2012b, Stricklin 2013a, Bull 1949, Bull 1954):

$$
\boldsymbol{y}=-2.59827+0.05868 x,
$$

where $y$ is the probit value and $x$ is the $\%$ TBSA. In this case, fluid plasma volumes for each corresponding $\%$ TBSA is correlated with that $\%$ TBSA probability of lethality. Hence, the fluid plasma minimum is mapped to risk of mortality. This mapping provides a dose-dependent mechanistic link for the effect of shock to the risk of mortality. The plasma volume minimums for the combined burn and radiation injury use the same mortality relationship and are used to estimate the 48-hour probability of mortality for the combined injury based on risk of shock.

\subsubsection{Comparison of 48-hour Mortality Risks}

The 48-hour mortality predictions based on MVES model outputs were compared to two other mortality estimates. One estimate for comparison was obtained from a 48-hour logistic regression model based on experimental combined burn and radiation injury (CI) data in rats that was then extrapolated to humans based on comparable probit relationships for mortality of the single injuries (see Stricklin 2013c; Alpen 1954, Anno 2003). The second estimate of mortality from different \% TBSA and radiation doses was obtained from the Consolidated Human Response Nuclear Effects Model (CHRNEM; Levin 1993a, Levin 1993b). CHRNEM predicts performance decrement from combined injury based on signs and symptoms; however, it does not make mortality predictions from combined injury. Nevertheless, CHRNEM was used to make correlations with probability of mortality from different levels of combined radiation and burn injuries. The correlations were based on the percent performance decrement observed at the maximal effect estimated for each of the combined insult simulations. The predicted mortality (or extrapolation) from each method (48-hour MVES, 48-hour logistic regression (CI), and CHRNEM) are compared in Table 11.

Table 11. Comparison of mortality estimates from the CSM, CI and CHRNEM models for combined injuries.

\begin{tabular}{|c|c|c|c|c|c|c|c|c|c|}
\hline \multirow{2}{*}{$\begin{array}{c}\text { Dose } \\
\text { Gy }\end{array}$} & \multicolumn{3}{|c|}{$20 \%$ TBSA } & \multicolumn{3}{|c|}{$\underline{40 \% \text { TBSA }}$} & \multicolumn{3}{|c|}{$\underline{60 \% \text { TBSA }}$} \\
\hline & MVES & $\mathrm{Cl}$ & CHRNEM & MVES & $\mathrm{Cl}$ & CHRNEM & MVES & $\mathrm{Cl}$ & CHRNEM \\
\hline 1 & 9 & 39 & 52.1 & 57.7 & 67.9 & 84.7 & 90.1 & 87.4 & 92 \\
\hline 2 & 12.3 & 47.4 & 55.6 & 79.9 & 74.8 & 85.9 & 99.1 & 90.7 & 92.6 \\
\hline 3 & 12.7 & 55.9 & 58.5 & 96.9 & 80.7 & 87.4 & 99.9 & 93.2 & 92.9 \\
\hline 4 & 60.3 & 64.1 & 64.6 & 99.9 & 85.5 & 89.6 & 99.9 & 95.1 & 92.9 \\
\hline 5 & 95.3 & 71.6 & 69.6 & 99.9 & 89.2 & 91.4 & 99.9 & 96.5 & 95.6 \\
\hline 6 & 99.9 & 78 & 71.8 & 99.9 & 92.1 & 91.7 & 99.9 & 97.5 & 96 \\
\hline 7 & 99.9 & 83.3 & 73.6 & 99.9 & 94.3 & 91.9 & 99.9 & 98.2 & 96.3 \\
\hline 8 & 99.9 & 87.5 & 79.7 & 99.9 & 94.4 & 92.4 & 99.9 & 98.7 & 96.6 \\
\hline
\end{tabular}

The greatest agreement between the models is observed at very high doses of radiation and \% TBSA, where high mortality is predicted. Greater variance is observed at lower doses. The 
MVES model predicts lower mortality at the lowest doses but rapidly increases at and predicts higher mortality than the CI model at different points. Additional model simulations were conducted to determine the radiation doses at which the predictions between the MVES and CI models cross over. The results are shown in Table 12; the bolded values indicate where the two models cross over in their predictions.

Table 12. Percent mortality predictions by MVES and CI for different combined injuries.

\begin{tabular}{|c|c|c|c|c|c|c|c|c|}
\hline \multirow{2}{*}{$\begin{array}{l}\text { FIA dose } \\
\text { Gy }\end{array}$} & \multicolumn{2}{|c|}{$\underline{20 \%}$ TBSA } & \multirow{2}{*}{$\begin{array}{l}\text { Rad FIA } \\
\text { Gy }\end{array}$} & \multicolumn{2}{|c|}{$\underline{40 \% \text { TBSA }}$} & \multirow{2}{*}{$\begin{array}{l}\text { Rad FIA } \\
\text { Gy }\end{array}$} & \multicolumn{2}{|c|}{$\underline{60 \% \text { TBSA }}$} \\
\hline & MVES & $\mathrm{Cl}$ & & MVES & $\mathrm{Cl}$ & & MVES & $\mathrm{Cl}$ \\
\hline 4 & 60.3 & 64.1 & 1.5 & 68.5 & 71.5 & 0.5 & 83.6 & 85.4 \\
\hline 4.1 & 64.3 & 64.9 & 1.6 & 70.8 & 72.2 & 0.6 & 84.7 & 85.9 \\
\hline 4.2 & 68.3 & 65.7 & 1.7 & 73.2 & 72.8 & 0.7 & 86 & 86.3 \\
\hline 4.3 & 72.4 & 66.5 & & & & 0.8 & 87.4 & 86.7 \\
\hline 4.4 & 76.4 & 67.2 & & & & & & \\
\hline 4.5 & 80.3 & 68 & & & & & & \\
\hline
\end{tabular}

The MVES prediction of mortality exceeds that of the CI prediction starting at 4.2, 1.7, and 0.8 Gy when combined with 20,40, and $60 \%$ TBSA, respectively. It is not certain whether the MVES model is no longer valid at these radiation doses. Based on data provided in Rosen 1988, endothelial cell killing contributes significantly to capillary permeability changes at 4 Gy and higher; however, no data was available on lower doses. Since the threshold for application of the radiation parameters for the MVES model cannot be determined with further certainty, we use the MVES model predictions up to the cross-over points with the CI logistic regression model until additional data becomes available to validate the model's applicability.

\subsection{Integration of Burn Effects into the Hematopoietic Models}

The physiological effects of thermal injury were incorporated into the three hematopoietic models discussed in section 3.1.1. For thrombopoiesis and granulopoiesis, models describing the effects of burn in mice were first developed. The structural changes determined through this model development were then applied to the human model. Parameters were determined using available data on platelet, granulocyte, and lymphocyte counts in humans following burn. A brief description of the model alterations are described below; for a more detailed description see DTRA-TR-15-024 (Wentz 2015d).

Examples for how burn affects the generic hematopoietic model are illustrated in Figure 19. In general, thermal injury potentially impacts the rate of cell death, the mediator level which further impacts the proliferation rate, and in some cases, increases the transition of progenitors into mature cells. 


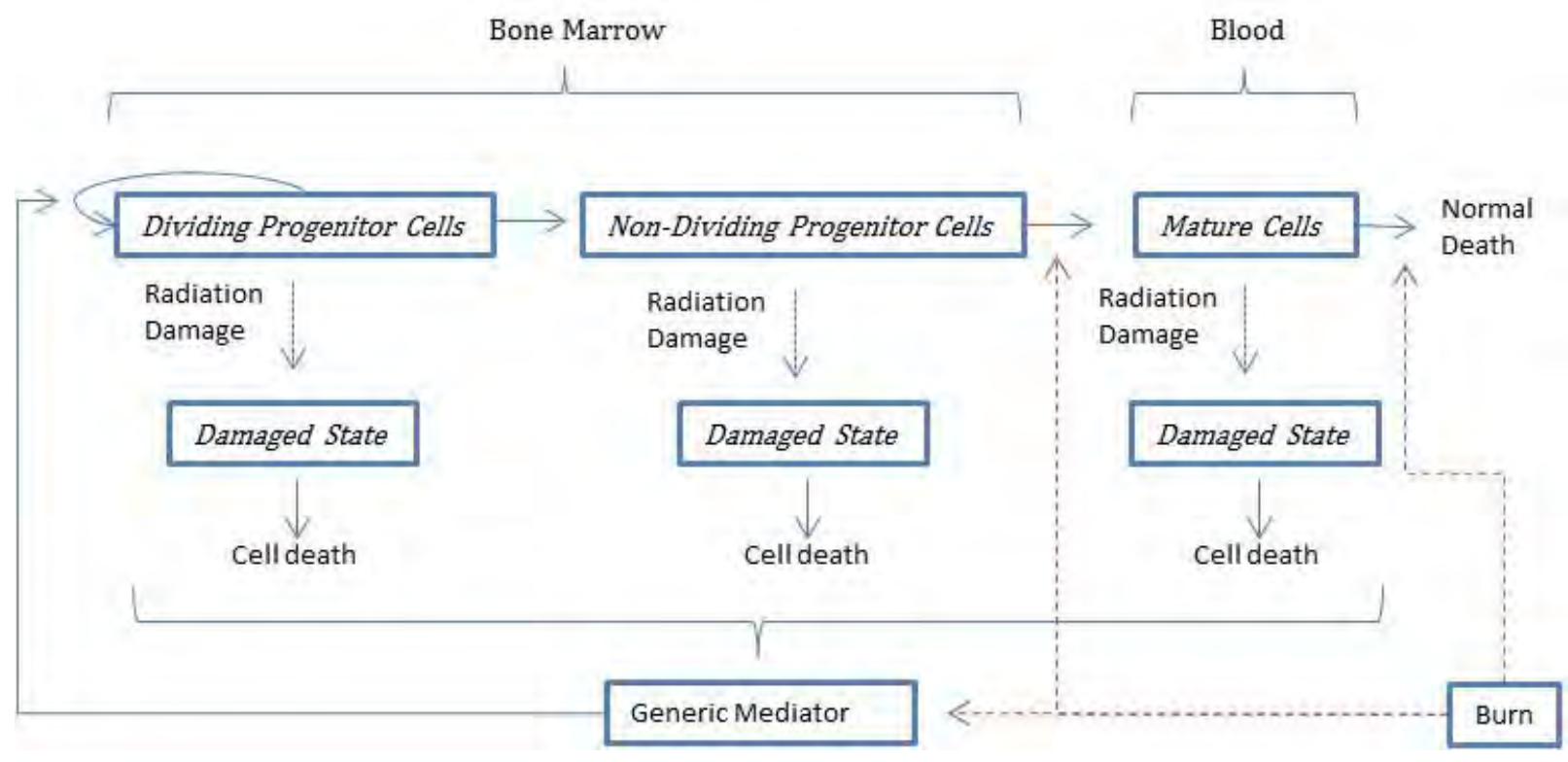

Figure 19. Diagram of the generic hematopoietic model structure with burn effects.

\subsubsection{Thrombopoiesis Model}

Following burn injury, a consistent, immediate, decrease in blood platelet counts is observed in human cases. After the initial decrease in platelet counts, the system over-compensates and goes into a sustained state of increased platelet levels. Therefore, to incorporate burn effects into the thrombopoiesis model, a dose-dependent, short-term decrease in platelet life-span and a longterm increase in mediator concentration were added to the model.

To determine the short-term decrease in platelet life-span, an altered platelet decay rate was derived. The altered platelet decay rate was quantified through the analysis of data taken directly from a study on platelet life-span following burn in humans (Simon 1977). The long-term increase in mediator concentration was based on levels of thrombopoietin (TPO). TPO levels are known to increase following burn, and, in the context of our model, TPO is the generic mediator that stimulates thrombopoiesis. Quantifying this alteration was done by optimizing the model to a retrospective study of platelet count kinetics following burn in humans (Marck 2013).

These changes were integrated into the thrombopoiesis model based on input of \% TBSA burn. An example of the model's output, peripheral platelet concentrations over time, overlaid with observational data (Marck 2013) is presented in Figure 20. The data represents the mean platelet count from subjects with $15-29 \%$ TBSA, and the simulation was run at the mean burn value of $21.5 \%$ TBSA. The solid black line and shaded area represent simulation results based on the mean initial observation and the range of normal platelet concentrations, respectively. The initial observation is the first platelet count observed in the burned human subjects, typically within hours of the burn incident. 


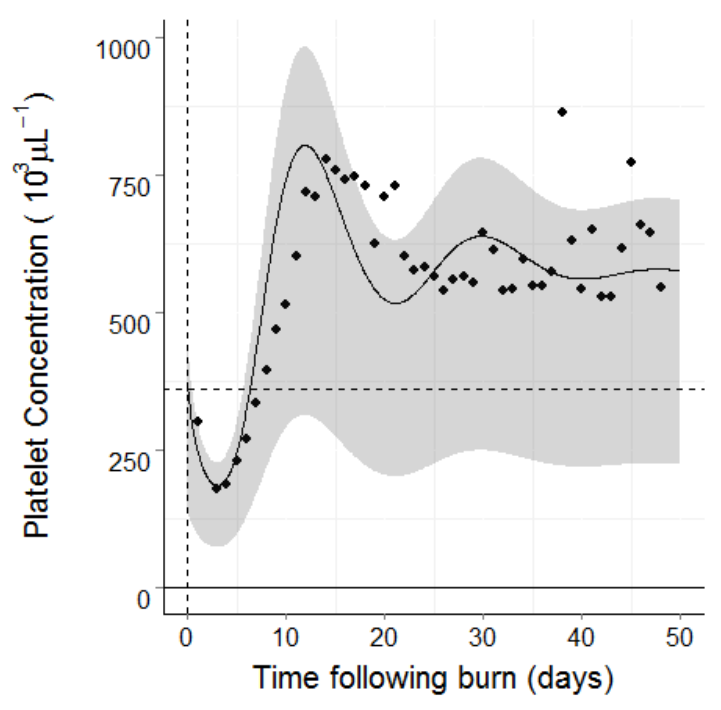

Figure 20. Simulated platelet concentrations for $21.5 \%$ TBSA compared to data from patients with $15-29 \%$ TBSA.

\subsubsection{Granulopoiesis Model}

Granulopoiesis is impacted by burn injury in several ways. Granulocytes in the blood can be either freely circulating or attached to the blood vessel wall. The pool of granulocytes that are attached to the vascular walls is referred to as marginated. Immediately after thermal injury, an increased number of granulocytes is observed, presumably due to demargination, meaning granulocytes detach from the epithelial lining of the blood vessels and return to the circulating pool (Summers 2010). The initial increase in granulocyte counts, following burn, is also thought to be a result of pre-mature granulocyte release from the non-dividing bone marrow compartment into the blood stream (Asko-Seljavaara 1974, Eurenius 1973, Volenec 1979). After the initial increases in circulating granulocytes, the levels return to normal due to an increased rate of influx of granulocytes into tissues, both at the site of injury and to some extent elsewhere (Hansbrough 1996). A second period of increased granulocyte counts are observed several days after burn injury due to increases in mediator concentrations, which stimulates the repopulation rate of dividing progenitor cells (Shoup 1998, Noel 2002).

For modeling these effects, the following changes were incorporated into the granulopoiesis model:

1. Increased demargination: A burn dependent effect on the proportion of marginated granulocytes was incorporated into the model.

2. Increased rate of bone marrow release: The transit time through the post-mitotic compartment is temporarily decreased by changing the rate of release of granulocytes from the bone marrow in the model.

3. Increased uptake of granulocytes in the tissues: The rate of granulocytes entry into tissues is mathematically adjusted by the level of burn for a period of time. 
4. Increased progenitor repopulation rate: In the model, thermal injury increases the maximum mitotic repopulation rate.

The resulting granulopoeisis model for burn was compared to human case study data used in optimization in Figure 21. The model simulation was performed for a mean burn value of 36\% TBSA and the case study data represented patients with 30-50\% TBSA (Peterson 1983). The solid black line and shaded region represent simulation results based on the mean and range of granulocyte concentrations observed in normal humans respectively. The simulation and data illustrate the early period of granulocytosis, followed by a decline, which rebounds after several days.

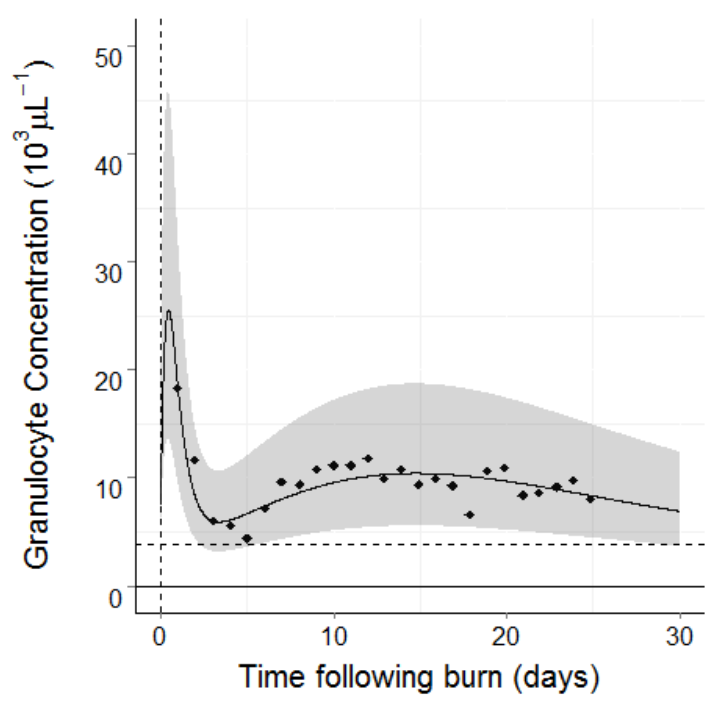

Figure 21. Simulated granulocyte concentrations for 36\% TBSA compared to data from patients with $30-50 \%$ TBSA.

\subsubsection{Lymphopoiesis Model}

Following thermal injury, a net decrease in the circulating lymphocytes is observed in human data (D’Arpa 2009, Kagan 1989, Neilan 1977). Different lymphocyte subpopulations respond differently after burn injury. Decreases in T lymphocytes are observed, while B cells and NK cells may be increased (Entezami 2010). However, there is not enough detailed data to adequately model lymphocyte subpopulations at this time. The net decline of lymphocytes is most likely due to increased adhesion and clearance of lymphocytes following thermal injury (Maldonado 1991).

The decrease in circulating lymphocytes was modeled by decreasing lymphocyte lifespan through increasing the rate of lymphocyte decay as a function of burn. Figure 22 shows an example of simulated lymphocyte concentrations for 59\% TBSA overlaid with burn data from patients with $43-74 \%$ TBSA. 


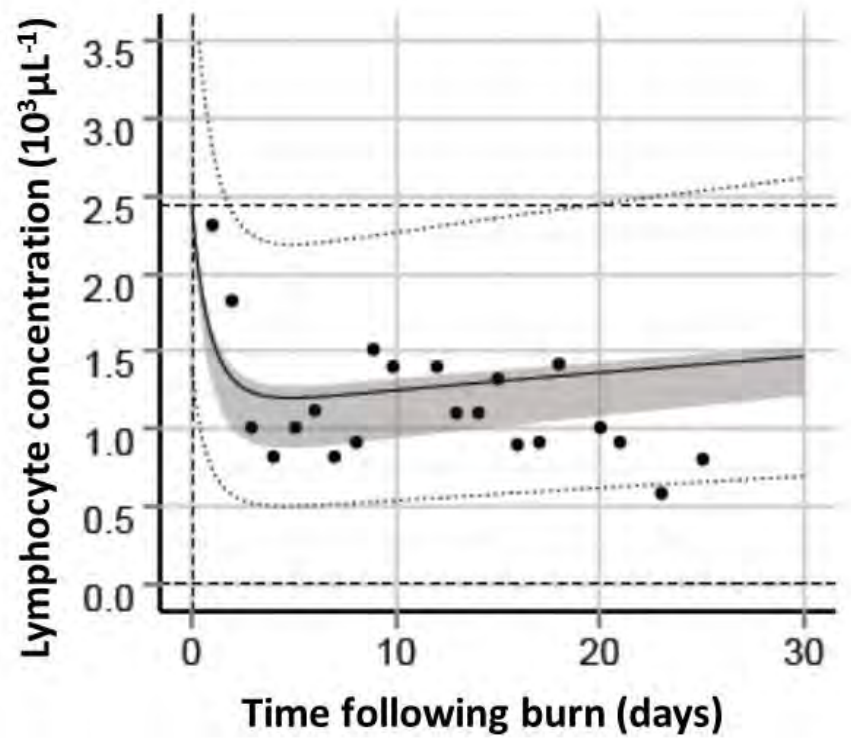

Figure 22. Simulated lymphocyte concentrations for 59\% TBSA compared to data from patients with $43-75 \%$ TBSA.

\subsubsection{Combined Radiation and Burn Injury Effects}

The thermal injury parameters were incorporated into the same radiation hematopoietic effects models in order to estimate the impacts of single or combined prompt injuries. Figure 23 shows an example of the combined injury simulation results. The simulation results for only burn (15 or $25 \%$ TBSA) or radiation exposure $(2.7 \mathrm{~Gy})$ are overlaid on the combined injury ( 15 or $25 \%$ TBSA and $2.7 \mathrm{~Gy}$ ) predictions for comparison.
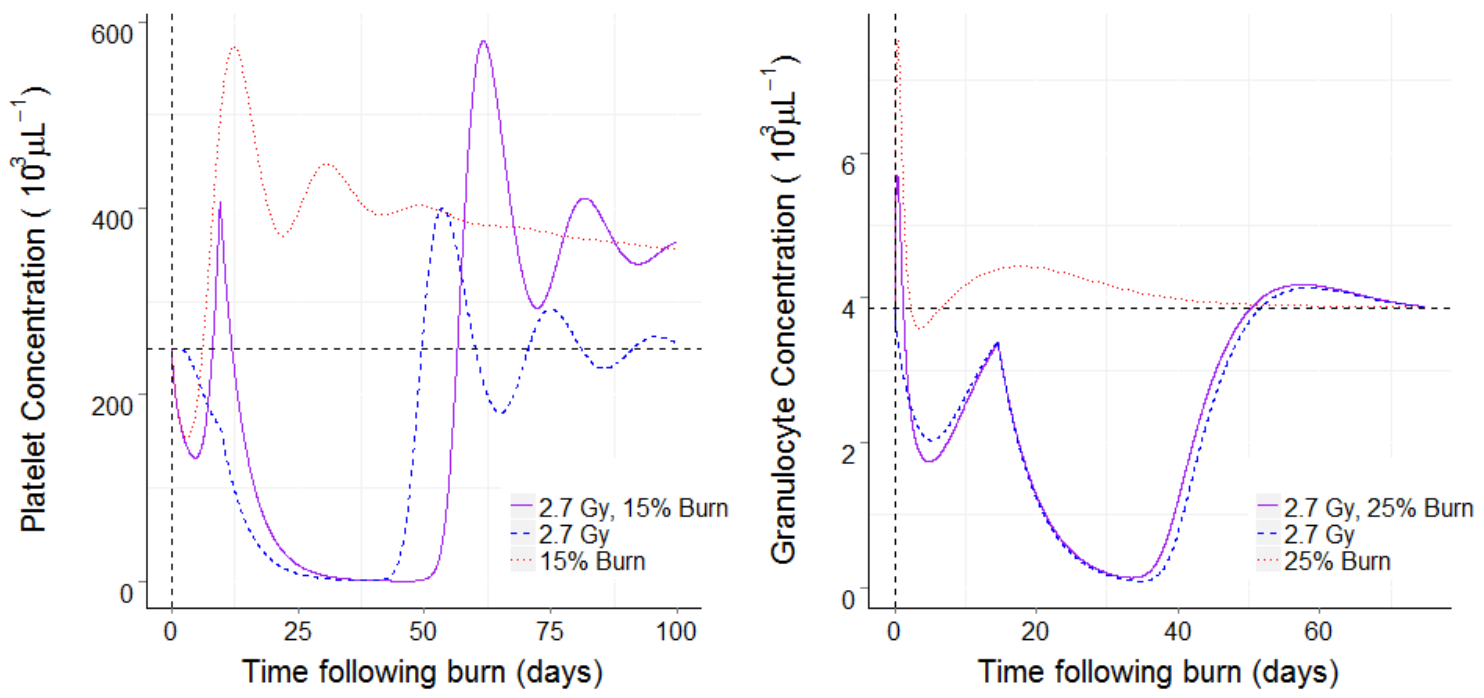

Figure 23. Simulated platelet and granulocyte concentrations after radiation, burn, and combined injury. 
With the moderate levels of injury used in the simulations shown in Figure 23, the response profile for CI mainly follows that of the radiation exposure, illustrating a delayed recovery of thrombocytes. Granulocytes may result in a deeper nadir from combined injury, but may also recover slightly faster due to the increase in proliferation rates induced by thermal injury. 


\section{Section 4.}

\section{Future HENRE Development}

HENRE development is an active project and new models will continue to be developed and implemented in the tool. The tool will continue to be expanded to further improve casualty estimation and to better understand both consequences of execution, as well as assisting in the medical planning process. In this section, we describe some near-term improvements that will be implemented into HENRE, as well as some longer-term research and development goals for future work.

\subsection{Additional Near-term Development}

Near-term development is aimed at completing the transition from empirical extrapolations and probit dose-response curves to basing casualty estimations fully on mechanistic model predictions. This will allow for the time course of injury and recovery to be detailed, more accurate combined injury evaluation, and the assessment of more advanced therapeutics on outcomes.

\subsubsection{Mapping clinical endpoints to outcomes}

An important aspect in transitioning away from probit-type of dose-response models to predictive mechanistic models is relating endpoints that are predicted by the mechanistic models to risk of mortality.

For the hematopoietic models, risk to several outcomes can impact the overall mortality risk. For example, when platelet levels are too low, the risk of hemorrhage is significant and is also associated with higher mortality risk. The relationship between platelet level and risk of hemorrhage needs to be delineated. Likewise, neutropenia results in a high risk of infection, which can also lead to sepsis and mortality. A statistical association between these risks are needed. In a recent non-human primate study, minimal levels of blood cell counts were statistically correlated with mortality after radiation exposure (Gluzman-Poltorak 2015). Additionally, several clinical studies have evaluated the thrombocytopenia as a predictor of mortality after acute injuries (Lee 1993, Vanderschueren 2000, Akca 2002). These types of statistical associations will be reviewed and adapted to enable time-dependent mortality risk estimates from the mechanistic models.

Similar to the hematopoietic models, outputs from the small intestine cell dynamic model (SIM) needs to be correlated with clinically relevant endpoints. With the loss of crypt cells and the integrity of the intestinal lining, GI failure can occur and the lack of functionality impairs absorption of essential nutrients. Permeability of the intestinal barrier increases allowing the loss of fluid, hemorrhage, and leakage of bacteria from the intestine into the blood stream, increasing the risk of sepsis. Independently, these effects impact mortality risks, but collectively with the compromised hematopoietic system, hemorrhage and infection risks are greatly increased. Therefore, in addition to mapping SIM outputs to effects, an understanding of how the effects observed in the small intestines intersect with hematopoietic effects are needed as well. 


\subsubsection{Integration of thermal injury effects on the GI system}

To adequately model the interim mortality risk of burn and radiation combined injury, the effect of burn on the GI system needs to be modeled. Thermal injury results in a cascade of systemically released mediators resulting in early permeability changes. The same permeability changes that lead to early circulatory shock risk can also impact the GI tract, resulting in compromised gut barrier function and potential bacterial translocation (Gosain 2005, Magnotti 2005). Parameters describing the impact of thermal injury on the GI system need to be developed and integrated into the SI model output in order to estimate the increased impact of thermal injury on the radiation effects in the GI system. Although, limitations in available data may dictate the level of detail in which these effects can be modeled.

\subsubsection{Validation of models and outputs}

Many of the mechanistic models and the mapping to outcomes need further validation. However, the level of validation possible is prohibited by the limited data available. In fact, many of the models could benefit from additional data. Future work in this area will be to explore additional data sources for validation of models or components of models. In some cases, if animal model parameters are developed, experimental animal data can be used to validate the model outputs. Future collaboration with experimentalists to test specific aspects of models could help the validation of the models. For combined injury, human data may be available from Hiroshima and Nagasaki, as well as Chernobyl to support validation of some of the combined injury predictions.

\subsubsection{Blast injuries}

As mentioned previously, a greater level of detail is needed in the types of blast injuries that are estimated to further inform medical response and resource planning. We have previously reviewed the blast injuries that occur from analogous scenarios: non-primary injuries from terrorist bombings that are representative of injuries from secondary blast effects, and earthquake injuries that are representative of injuries resulting from building collapse. Proportionalities for different injury types from these data will be used together with the current environment and casualty estimations to provide detailed injury assessments.

\subsection{Future Development}

A number of other modeling needs exist and are planned for the future. A few of the known gaps are highlighted in the following sections.

\subsubsection{Modeling of traumatic injuries}

The variety of different injuries that can result from the blast effects of nuclear environments include injuries from direct displacement, such as blunt trauma, broken limbs, and concussions; from flying debris, such as penetrating injuries and lacerations from glass breakage; and from building collapse, such as crush injuries. Due to the vast number of different traumatic injury types, physiological modeling of each is prohibitive. However, radiation combined with these injuries do have an additive, if not synergistic, impact on observed effects, resulting in more 
earlier and more severe outcomes and delayed recovery. To adequately address traumatic combined injury, some higher level, statistical models may be required for general use. Certain traumatic injuries that predominate and have applicability in other analysis areas may warrant mechanistic modeling. For example, several hemorrhage models exist; these models could be adapted to account for the added effects of radiation by connecting with the hematopoietic models. This would help predict the impact of radiation with traumatic injuries where significant blood loss occurs and help understand the time to recover for those individuals.

Another area where synergistic effects of traumatic injuries may warrant mechanistic modeling is with pulmonary effects. As observed with burn and radiation acute injury, significant traumatic injuries result in the immediate release of mediators into the circulation. These mediators result in permeability changes and fluid shifts. In severe injuries, these changes can also affect pulmonary function as a result of pulmonary edema. These effects are generally secondary to the direct effects of the injury; however, they exist and may become more prominent in combined injuries and affect overall outcomes. These effects would certainly become predominate in cases where inhalation exposures of smoke, dust, or toxic fumes occurred. In fact, the most dominate injury from residential building fires is smoke inhalation and significantly contributes to the observed fatalities in these incidents (DHS 2012). Therefore, these pulmonary effects warrant further investigation in the future.

\subsubsection{Other modeling efforts}

Extensive variability in response to injury is observed across the population. Studies have shown that factors such as age, gender, genetic disposition, and health status can influence individual response to injury. Individual variability can arise from differences in immune response, molecular repair mechanisms, or metabolism. Demographic differences that can potentially influence response to radiation injury include in utero exposures, age, gender, genetic susceptibility, and co-morbidity factors. The existing data on demographic variability in radiation response surveyed to find prominent demographic factors affect acute radiation response (Stricklin 2012c). The work was focused on human data and acute radiation effects with an emphasis on mortality risks. Based on the findings of that work, modification factors will be developed to model the variability in subpopulation responses to radiation.

Another factor in radiation exposure scenarios is the fact that exposures are rarely uniform, whole-body exposures. In most cases, part of the body receives a higher dose than the rest, resulting in variable dose to critical organs depending on their locations. The modified lethality of partial-body exposures has been demonstrated in animal experiments (MacVittie 2012). Therefore, a partial-body exposure model could help better understand the impacts of partialbody exposures and could provide insight on the modified mortality risk and benefit of treatment in these cases. Preliminary work using a compartmentalized MarCell to understand the impact of partial-body radiation on bone marrow populations has been undertaken (Li 2012). This work will be explored further in the future.

Another critical aspect that affects mortality in nuclear and radiological scenarios is the radiation dose received to the skin as a result of fallout. Depending on the level and type of radioactivity, skin contamination can result in high localized doses to the skin and can cause cutaneous injury. The skin serves as a critical organ, acting as a barrier against bacteria, and is the body's first line of defense against infection. Cutaneous injury was shown to play a prominent role in mortality 
of Chernobyl patients (Gottlöber 2001, Mettler 2007). Understanding the impact of cutaneous doses not only is important for estimating health effects, but is also key in developing appropriate guidelines for responders and decontamination protocols. Modeling of cutaneous radiation doses, injury, and added physiological impacts is an important topic to address in the future.

One additional factor that may impact casualty estimation is the use of advanced treatments, such as cytokines, to alleviate symptoms of ARS. While the feasibility of treating large populations was previously not realistic, more recently, G-CSF has been approved for the treatment of ARS and has been included in the Strategic National Stockpile (SNS) and the User's Managed Inventory (UMI). Therefore, a significant number of treatments may be feasible for a larger scale accident. A mechanistic model would aid in understanding which patients would most benefit from treatments. For example, the hematopoietic cell kinetic models are well designed to incorporate cytokine treatment and could be used together with the combined injury models. Sufficient data exists for G-CSF, and it may be incorporated as a treatment option in our model in the future. Likewise, several other treatment options, such as fluid resuscitation for burn injury, may be included in the HENRE models in the future.

\subsubsection{Modeling of manifest GI syndrome}

The manifest or last phase of GI syndrome is not well understood and is currently not modeled in RIPD or HENRE. The manifest effects do not appear to be directly related to the crypt cell kinetics, but one hypothesis suggests that the observed diarrhea symptomology during this phase is due to hematopoietic failure and the lack of support from the blood system (Anno 1991). The hematopoietic models do, in fact, show that granulocyte and platelet levels reach minimums at approximately 4 weeks following radiation exposure, which is in agreement with blood cell data from radiation accident victims (Wentz 2014). Furthermore, in cancer patients treated with radiotherapy, erythrocyte concentrations also reached a nadir at approximately 4 weeks following exposure (Miller 1958). However, further research is needed to address the manifest phase of GI syndrome. If warranted, this component of ARS will be addressed in the future. 


\section{Section 5.}

\section{Summary}

This report provided an overview of the technical and scientific basis of the models incorporated in the Health Effects from Nuclear and Radiological Environments (HENRE) code. This report described the current release of the HENRE tool incorporate models developed for casualty estimation associated with prompt environments generated from a nuclear detonation. Two suites of models are included in the HENRE tool; the Basic Casualty Estimation Tool and the Advanced Casualty Estimation Tool and this report describes the rationale and approaches used for each new model that has been implemented.

This report described the background and implementation of the current models in the HENRE 2.0 version as of the publication date of this report. New models and capabilities will continue to be added to HENRE and near-term plans and future modeling needs were also discussed.

Note that the HENRE software code has distribution restricted to authorized U.S. government users and contractors. It is available upon request from the DTRA Program Manager, Code J9NTSN; see Report Documentation Page (SF 298) in the front of this report for contact information. 


\section{Section 6.}

\section{References}

Akca S, Haji-Michael P, de Mendonça A, Suter P, Levi M, Vincent JL., 2002. "Time course of platelet counts in critically ill patients." Crit Care Med.30(4):753-6.

Alpen, E.L., Sheline, G.E., 1954. "The Combined Effects of Thermal Burns and Whole Body X Irradiation on Survival Time and Mortality," Annals of Surgery, 140(1):113-118.

Anno, G.H., Wilson, D.B., and Dore, M.A., 1984. Nuclear Weapons Effect Research at PSR, 1983: Acute Radiation Effects on Individual Crewmember Performance. DNA-TR-85-52, Defense Nuclear Agency, Alexandria, VA.

Anno, G. H., Wilson, D.B., and Baum, S.J., 1985. Severity Levels and Symptom Complexes for Acute Radiation Sickness: Description and Quantification. DNA-TR-86-94, Defense Nuclear Agency, Alexandria, VA.

Anno, G.H., Baum, S.J., Withers, H.R., and Young, R.W., 1989. "Symptomatology of Acute Radiation Effects in Humans after Exposure to Doses of 0.5-30 Gy," Health Physics, 56(6):821-838.

Anno, G.H., McClellan, G.E., Dore, M.A., and Baum, S.J., 1991. Biological Effects of Protracted Exposure to Ionizing Radiation: Review, Analysis, and Model Development. DNA-TR-90-157, Defense Nuclear Agency, Alexandria, VA.

Anno, G.H., Dore, M.A., Roth, J.T., LaVine, N.D., and Deverill, A.P., 1994. Predicted Performance of Infantry and Artillery Personnel Following Acute Radiation or Chemical Agent Exposure. DNA-TR-93-174, Defense Nuclear Agency, Alexandria, VA.

Anno, G.H., McClellan, G.E., and Dore, M.A., 1996. Protracted Radiation-Induced Performance Decrement Vol 1 - Model Development. DNA-TR-95-117-V1, Defense Nuclear Agency, Alexandria, VA.

Anno, G.H., Young, R.W., Bloom, R.M., and Mercier, J.R., 2003. "Dose Response Relationships for Acute Ionizing-radiation Lethality," Health Physics, 84(5):565-575.

Ampratwum, R.T., Bowen, B.D., Lund, T., Reed, R.K, and Bert, J.L., 1995. "A Model of Fluid Resuscitation Following Burn Injury: Formulation and Parameter Estimation," Computer Methods and Programs in Biomedicine, 47(1):1-19.

Arturson, G., Groth, T., Hedlund, A., and Zaar, B., 1984 "Potential Use of Computer Simulation in Treatment of Burns with special regard to Oedema Formation". Scandinavian Journal of Plastic and Reconstructive Surgery, 18(1):39-48.

Asko-Seljavaara, S., 1974. "Granulocyte Kinetics in Burned Mice. Inhibition of Granulocyte Studied In Vivo and In Vitro," Scandinavian Journal of Plastic and Reconstructive Surgery, 8(3):185-191.

Barrett, K., Brooks, H., Boitano, S., and Barman, S., 2010. Ganong's Review of Medical Physiology. 23rd edition. The McGraw-Hill Companies, Inc., New York, NY. 
Barker, N., Es, J.H., Kuipers, J., Kujala, P., Born, M., Cozijnsen, M., Haegebarth, A., Korving, J., Begthel, H., Peters, P.J., and Clevers, H., 2007. "Identification of Stem Cells in Small Intestine and Colon by Marker Gene Lgr5." Nature, 449(7165):1003-1007.

Baum, S.J., 1991. The Pathophysiology of Combined Radiation Injuries: A Review and Analysis of the Literature on Non-human Research. DNA-TR-90-211, Defense Nuclear Agency, Technico Southwest, Inc., Los Alamos, NM.

Baum, S.J., Anno, G.H., Young, R.W., and Withers, H.R., 1984. Nuclear Weapon Effect Research at PSR -Symptomatology of Acute Radiation Effects in Humans after Exposure to Doses of 75 to 4500 Rads (cGy) Free-In-Air. DNA-TR-85-50, Defense Nuclear Agency, Alexandria, VA.

Beale, J. P., Wyatt, J. P., Beard, D., Busuttil, A., and Graham, C. A., 2000. “A five year study of high falls in Edinburgh," Injury, 31(7), 503-8.

Bert, J., Gyenge, C., Bowen, B., Reed, R., Lund, T., 1997. "Fluid Resuscitation Following a Burn Injury: Implications of a Mathematical Model of Microvascular Exchange," Burns, 23(2):93-105.

Bond, V.P., Fliedner, T.M., and Archambeau, J.O., 1965. Mammalian Radiation Lethality: A Disturbance in Cellular Kinetics. Academic Press, New York, NY.

Booth, C., Tudor, G., Tudor, J., Katz, B.P., and MacVittie, T.J., 2012a. "Acute Gastrointestinal Syndrome in High-Dose Irradiated Mice,” Health Physics, 103(4):383-399.

Booth, C., Tudor, G., Tudor, J., Shea-Donohue, T., and MacVittie, T.J., 2012b. "Evidence of Delayed Gastrointestinal Syndrome in High-dose Irradiated mice," Health Physics, 103(4):400-410.

Bowen, I. G., Albright, R. W., Fletcher, E. R., and White, C. S., 1961. A Model Designed to Predict the Motion of Objects Translated by Classical Blast Waves. CEX-58.9, Lovelace Foundation for Medical Education and Research, Albuquerque, New Mexico.

Brooks, P.M., H.B. Gerstner, and S.A. Smith, 1956. "Early Vasoconstriction Induced in the Isolated Rabbit's Ear by X-radiation," Radiation Research, 4(6):500-509.

Bull, J.P., Squire, J.R., 1949. "A Study of Mortality in a Burns Unit: Standards for the Evaluation of Alternative Methods of Treatment," Annals of Surgery, 130(2):160-173.

Bull, J.P., Fisher, A.J., 1954. “A Study of Mortality in a Burns Unit: a Revised Estimate,” Annals of Surgery, 139(3):269-274.

Cairnie, A.B., and Millen, B.H., 1975. "Fission of Crypts in the Small Intestine of the Irradiated Mouse." Cell and Tissue Kinetics, 8(2):189-196.

Cohn, S.H., and Milne, W.L., 1956. The Effects of Combined Administration of Strontium-90 and External Radiation. USNRDL-TR-89, Naval Radiological Defense Lab., San Francisco, CA.

D’Arpa, N., Accardo-Palumbo, A., Amato, G., D'Amelio, L., Pileri, D., Cataldo, V., Mogavero, R., Lombardo, C., Napoli, B., and Conte, F., 2009. "Circulating Dendritic Cells following Burn," Burns, 35(4):513-8. 
Dainiak, N., Gent, R.N., Carr, Z., et al., 2011. "Literature Review and Global Consensus on Management of Acute Radiation Syndrome Affecting Nonhematopoietic Organ Systems." Disaster Medicine and Public Health Preparedness, 5(3):183-201.

Department of the Army, 2013. Personnel Risk and Casualty Criteria for Nuclear Weapons Effects. DA PAM 50-7, Washington, D.C.

Department of Homeland Security (DHS), 2012. Civilian fire injuries in residential buildings (2008-2010). US Department of Homeland Security/US Fire Administration, National Fire Data Center. Topical Fire Report Series; 13(3):1-12.

Dickinson, A., Roberts, M., Kumar, A., Weaver, A., and Lockey, D. J., 2012. "Falls from height: injury and mortality," Journal of the Royal Army Medical Corps, 158(2), 123-7.

Drake, M., and Woolson, W., 1993. "Chapter 14-Effects on Personnel," Effects Manual-1: Capabilities of Nuclear Weapons. Alexandria. Defense Nuclear Agency.

Drake, M. K., Fricke, M. P., Groce, D. E., Kaul, D. C., Rindfleisch, C. J., Swenson, J. B., and Woolson, W. A., 1978. An Interim Report of Collateral Damage. DNA 4734Z, Science Applications, Inc., Lajolla, California.

Eassa, E.H., and Casarett, G.W, 1973. "Effect of Epsilon-amino-n-caproic Acid (EACA) on Radiation-induced Increase in Capillary Permeability," Radiology, 106(3):679-688.

Entezami, K.Z., Khosravi, A., Mousavi, T., and Bahar, M.A., 2010. "Immunophenotype of Peripheral Blood Lymphocytes following Thermal Injury in Patients," Medical Journal of the Islamic Republic of Iran, 24(2):96-102.

Eurenius, K., and Brouse, R.O., 1973. "Granulocyte Kinetics after Thermal Injury," American Journal of Clinical Pathology, 60(3):337-342.

Evans, M.L, Graham, M.M., Mahler, P.A., and Rasey, J.S., 1986. "Changes in Vascular Permeability following Thorax Irradiation in the Rat," Radiation Research, 107(2):262271.

Fletcher, E. R., and Bowen, I. G., 1966. Blast-Induced Translational Effects. DASA 1859, Lovelace Foundation for Medical Education and Research, Albuquerque, New Mexico.

Fletcher, E. R., Yelverton, J. T., Hutton, R. A., and Richmond, D. R., 1975. Probability of Injury from Airblast Displacement as a Function of Yield and Range. DNA 3779T, Lovelace

Gabryś, D., Greco O., Patel G., Prise, K.M., Tozer, G.M., and Kanthou, C., 2007. "Radiation Effects on the Cytoskeleton of Endothelial Cells and Endothelial Monolayer Permeability," International Journal of Radiation Oncology • Biology • Physics, 69(5):1553-1562.

Geiger, K. (1964) Grundlagen der Militarmedizin, Berlin. As cited from O. Messerschmidt, Results of Animal Experiments as a Basis for Recommendations on Therapy of Combined Injuries (Radiation Injury Plus Wounds). In The Pathophysiology of Combined Injury and Trauma (Walker, R.I., Gruber, D.F., MacVittie, T.J., and Conklin, J.J.) Armed Forces Radiobiology Research Institute, Bethesda, Maryland, pp 36-50; 1983. 
Gluzman-Poltorak Z, Vainstein V, Basile LA., 2015. “Association of Hematological Nadirs and Survival in a Nonhuman Primate Model of Hematopoietic Syndrome of Acute Radiation Syndrome." Radiation Research. 184(2):226-30.

Goans, R., 2010. Medical Management of Radiological Casualties, $3^{\text {rd }}$ Edition. Armed Forces Radiobiology Research Institute, Bethesda, MD.

Gómez-Cía, T., Roa, L., 1993. “A Burn Patient Resuscitation Therapy Designed by Computer Simulation (BET). Part 2: Initial Clinical Validation," Burns. 19(4):332-8.

Gosain A, Gamelli RL., 2005. "Role of the gastrointestinal tract in burn sepsis." Journal of Burn Care and Rehabilitation, 26(1):85-91.

Gottlöber P, Steinert M, Weiss M, Bebeshko V, Belyi D, Nadejina N, et al., 2001. "The outcome of local radiation injuries: 14 years of follow-up after the Chernobyl accident." Radiation Research, 155(3):409-16.

Hansbrough, J. F., Wikstrom, T., Braide, M., Ph, D., Tenenhaus, M., Rennekamp O. H., Kiessig, V., and Bjursten, L. M., 1996. "Neutrophil activation and tissue neutrophil sequestration model of thermal injury in a rat," Journal of Surgical Research, 61(1), 17-22.

Harris, J.W., and Nonan, T.R., 1968. "Early Vascular Permeability Changes in Whole-body Xirradiated Rats," Radiation Research, 34(2):357-365.

Hedlund, A., Zaar, B., Groth, T., Arturson, G., 1988. “Computer Simulation of Fluid Resuscitation in Trauma. I. Description of an Extensive Pathophysiological Model and its First Validation," Computer Methods and Programs in Biomedicine, 27(1):7-21.

Hurt, H. H., Ouellet, J. V., and Thom, D. R., 1981a. Volume I: Techinical Report. Motorcycle Accident Cause and Factors Identification of Countermeasures. Traffic Safety Center, University of Southern California, Los Angeles, CA.

Hurt, H. H., Ouellet, J. V., and Thom, D. R., 1981b. Volume II: Appendix/Supplemental Data. Motorcycle Accident Cause and Factors Identification of Countermeasures. Traffic Safety Center, University of Southern California, Los Angeles, CA.

Joiner, M.C., 2009. Chapter 4: Quantifying Cell Kill and Cell Survival. Basic Clinical Radiobiology Fourth Edition, CRC Press, Claremont, FL.

Jones, T.D., Morris, M.D., and Hasan, J.S., 1996. Environmental Risk Assessments Based on Bone Marrow Cell Kinetic. DNA-TR-94-99, Defense Nuclear Agency, Alexandria, VA. February

Kagan, R.J., Bratescu, A., Jonasson, O., Matsuda, T., and Teodorescu, M., 1989. “The Relationship between the Percentage of Circulating B Cells, Corticosteroid Levels, and Other Immunologic Parameters in Thermally Injured Patients," The Journal of Trauma, 29(2):208-13.

Kelley, D.M., 2005. "Hypovolemic Shock: an Overview," 2005. Critical Care Nursing Quarterly, 28(1):2-19.

Krishnan, L., Krishnan, E.C., Jewell, W.R., 1988. "Immediate Effect of Irradiation on Microvasculature," International Journal of Radiation Oncology • Biology • Physics, 15(1):147-150. 
Lapostolle, F., Gere, C., Borron, S. W., P'etrovic, T., Dallemagne, F., Beruben, A., Lapandry, C., and Adnet, F., 2005. "Prognostic factors in victims of falls from height," Critical Care Medicine, 33(6), 1239-42.

Latenser, B.A., 2009. "Critical Care of the Burn Patient: the First 48 hours," Critical Care Medicine, 37(10):2819-2826.

Lee KH, Hui KP, Tan WC., 1993. "Thrombocytopenia in sepsis: a predictor of mortality in the intensive care unit." Singapore Medical Journal, 34(3):245-6.

Leach, R.M., Ward, J.P.T., Sylvester, J.T., 2004. Chapter 4: Shock. Critical Care Medicine at a Glance. Wiley-Blackwell, Malden, MA.

Levin, S.G., 1993a. The Effect of Combined Injuries from a Nuclear Detonation on Soldier Performance. DNA-TR-92-134, Defense Nuclear Agency, Alexandria, VA.

Levin, SG. 1993b. Consolidated Human Response Nuclear Effects Model (CHRNEM). DNATR-93-45, Defense Nuclear Agency, Alexandria, VA.

Levin, S.J., and Fulton, J.W., 1993. Consolidated Human Response Nuclear Effects Model (CHRNEM). AD-B176 745, Defense Nuclear Agency, Alexandria, VA.

Li A, Oldson D, Millage K, Stricklin D., 2012. An Approach to Predicting Hematopoietic Lethality from Partial Body Exposure to Ionizing Radiation. ARA/HS-TM-12-016-A, ARA Technical Note for DTRA, Applied Research Associates, Arlington, VA.

Li, X.H., Ghosh, S.P., Ha, C.T., Fu, D., Elliott, T.B., Bolduc, D.L., Villa, V., Whitnall, M.H., Landauer, M.R., and Xiao, M., 2013. "Delta-tocotrienol Protects Mice from Radiationinduced Gastrointestinal Injury," Radiation Research, 180(6):649-57.

Lin, C.C., and Segel, L.A., 1974. Mathematics Applied to Deterministic Problems in the Natural Sciences. Macmillan, New York, NY.

MacVittie TJ, Bennett A, Booth C, Garofalo M, Tudor G, Ward A, et al., 2012 "The Prolonged Gastrointestinal Syndrome in Rhesus Macaques: The Relationship Between Gastrointestinal, Hematopoietic, and Delayed Multi-organ Sequelae Following Acute, Potentially Lethal, Partial-body Irradiation." Health Physics, 103(4):427-53.

Magnotti LJ, Deitch EA., 2005. "Burns, bacterial translocation, gut barrier function, and failure." Journal of Burn Care and Rehabilitation, 26(5):383-91.

Maldonado, M.D., Venturoli, A., Franco, A., and Nunez-Roldan, A., 1991. "Specific Changes in Peripheral Blood Lymphocyte Phenotype from Burn Patients. Probable Origin of the Thermal Injury-related Lymphocytopenia," Burns, 17(3):188-92.

Marck, R.E., Montagne, H.L., Tuinebreijer, W.E., and Breederveld, R.S., 2013. "Time Course of Thrombocytes in Burn Patients and its Predictive Value for Outcome," Burns, 39(4):71422.

Matheson, L.N., Dore, M.A., Anno, G.H., and McClellan, G.E., 1998. User's Manual: Radiation-Induced Performance Decrement (RIPD), Version 2.0. DNA-TR-95-91, Pacific-Sierra Research Corp., Santa Monica, CA. 
Mercier, J. R., 2001. "Human Response Criteria for Blast Effects," Presentation at the Defense Threat Reduction Agency Human Response Panel Meeting, October 9th, 2001 (Unpublished Data).

Mettler Jr FA, Gus' kova AK, Gusev I., 2007. "Health effects in those with acute radiation sickness from the Chernobyl accident." Health Physics. 93(5):462.

Miller, L. S., Fletcher, G. H., and Gerstner, H. B., 1958. "Radiobiologic observations on cancer patients treated with whole-body x-irradiation." Radiation research, 8(2), 150-65.

Mount, D., and Bruce, W.R., 1964. "Local Plasma Volume and Vascular Permeability of Rabbit Skin After Irradiation," Radiation Research, 23:430-445.

Murphy, E.A., and Francis, M.E., 1971. "The Estimation of Blood Platelet Survival. II. The Multiple Hit Model," Thrombosis et Diathesis Haemorrhagica, 25(1):53-80.

NATO, 2011. AMedP-8(C): NATO Planning Guide for the Estimation of CBRN Casualties. p.225. Army Medical Publication-8 (C).

Neilan, B.A., Taddeini, L., and Strate, R.G., 1977. "T Lymphocyte Rosette Formation after Major Burns," Journal of the American Medical Association, 238(6):493-496.

Needham, C. E., 2010. Blast Waves. Springer, Berlin, Heidelberg, 152.

Noel, J.G., Valente, J.F., Ogle, J.D., Cornelius, J., Custer, D.A., Li, B.G., Alexander, J.W., and Ogle, C.K., 2002. "Changes in Bone Marrow-derived Myeloid Cells from Thermally Injured Rats Reflect Changes in the Progenitor Cell Population," Journal of Burn Care \& Rehabilitation, 23(2):75-86.

Oldson, D., 2013. HENRE Technical Reference Manual, HENRE Engine Rev. 17 (01 Nov 2013). ARA/HS-TM-13-014-A, ARA Technical Report for DTRA, Applied Research Associates, Arlington, VA.

Oldson, D., Stricklin, D., Wentz, J., et al., 2015. HENRE 2.0 - Technical Reference Manual. DTRA-TR-15-071, Defense Threat Reduction Agency, Fort Belvoir, VA.

Otte, D., 2001. "Importance of speed related traces on the scene for determination of collision speed in pedestrian and bicycle accidents," The Institute of Traffic Accident Investigators. Proceedings of the 5th International Conference: 17th and 18th November, 2001, 93-9.

Panés, J., Anderson, D.C., Miyasaka, M., and Granger, D.N., 1995. "Role of Leukocyteendothelial Cell Adhesion in Radiation-induced Microvascular Dysfunction in Rats," Gastroenterology, 108(6):1761-1769.

Pellmar, T.C., and Oldson, D.R., 2012a. A Critical Review of Selected Components of RIPD (Radiation-Induced Performance Decrement). DTRA-TR-12-047, Defense Threat Reduction Agency, Fort Belvoir, VA.

Pellmar, T.C., and Reeves, G.I., 2012b. Hematopoiesis Primer for Modeling Combined Injury. DTRA-TR-12-016, Defense Threat Reduction Agency, Fort Belvoir, VA.

Peterson, V., Hansbrough, J., Buerk, C., Rundus, C., Wallner, S., Smith, H., and Robinson, W.A., 1983. "Regulation of Granulopoiesis following Severe Thermal Injury," The Journal of Trauma, 23(1):19-24. 
Pham, T.N., Cancio, L.C., and Gibran, N.S., 2008. "American Burn Association Practice Guidelines Burn Shock Resuscitation," Journal of Burn Care and Research, 29(1):257266.

Reeves, G. I., 2015. “Chapter 14-Effects on Personnel, Revision 1,” Effects Manual-1: Capabilities of Nuclear Weapons. DTRA-EM-1-CH14 (R1). Fort Belvoir, VA.

Roa, L., and Gómez-Cía, T., 1993. “A Burn Patient Resuscitation Therapy Designed by Computer Simulation (BET). Part 1: Simulation studies,” Burns, 19(4):324-31.

Rosen, E.M., and Goldberg, I.D., 1998. Chapter 5: Protein Synthesis in Irradiated Endothelial Cells. The Radiation Biology of the Vascular Endothelium, D.B. Rubin, CRC Press, Washington, DC.

Shaw, A., Anderson, J., Hayward, A., and Parkhouse, N., 1994. "Pathophysiological Basis of Burn Management," British Journal of Hospital Medicine, 52(11):583-587.

Shoup, M., Weisenberger, J.M., Wang, J.L., Pyle, J.M., Gamelli, R.L., and Shankar, R., 1998. "Mechanisms of Neutropenia Involving Myeloid Maturation Arrest in Burn Sepsis," Annals of Surgery, 228(1):112-122.

Simon, T.T.L., Curreri, P.W., Seattle, L.A.H., and Harker, L., 1977. "Kinetic Characterization of Hemostasis in Thermal Injury," The Journal of Laboratory and Clinical Medicine, 89(4):702-711.

Smirnova, O.A., 2010. Environmental Radiation Effects on Mammals. Springer, New York, NY.

Smirnova, O.A., 2012. "Comparative Analysis of the Dynamics of Thrombocytopoietic, Granulocytopoietic, and Erythropoietic Systems in Irradiated Humans: a Modeling Approach," Health Physics, 103(6):787-801.

Song, C.W., Anderson, R.S., and Tabachnick, J., 1966. "Early Effects of Beta Irradiation on Dermal Vascular Permeability to Plasma Proteins," Radiation Research, 27(4):604-615.

Stricklin, D., Pellmar, T., and Oldson, D., 2010a. Literature Survey for Combined Injury Modeling. ARA/HS-TM-11-005, ARA Technical Memo for DTRA, Applied Research Associates, Arlington, VA.

Stricklin, D., Pellmar, T., Oldson, D., and Millage, K., 2010b. Combined Injury Modeling: Radiation and Burn Workshop Report. DTRA-TR-10-48, Defense Threat Reduction Agency, Fort Belvoir, VA. October.

Stricklin, D., 2012a. Review of Radiation Effects on Vascular Permeability. ARA-HS-TN-12020-A, Applied Research Associates, Arlington, VA.

Stricklin, D., and Li, A., 2012b. Development of a 48-hour Untreated Burn Mortality Probit Model. ARA/HS-TN-12-014-A, ARA Technical Note, Applied Research Associates, Arlington, VA.

Stricklin D, Millage K., 2012c. "Evaluation of Demographic Factors That Influence Acute Radiation Response." Health Physics, 103(2):210-6.

Stricklin, D., 2013a. Mapping the Couple Starling Model (CSM) Outputs to Mortality Predictions for Burn Shock. ARA-HS-TN-13-002-A, Applied Research Associates, Arlington, VA. 
Stricklin, D., 2013b. Estimation of Radiation Permeability Parameters for Integration into the CSM Model. ARA-HS-TN-13-012-A, ARA Technical Note, Applied Research Associates, Arlington, VA.

Stricklin, D., 2013c. Development of a Logistic Regression Model for Radiation and Combined Injury Mortality. ARA-HS-TN-13-009-A, Applied Research Associates, Arlington, VA.

Stricklin, D., 2013d. Overview of Burn Shock Pathophysiology. ARA/HS-TN-13-001-A, ARA Technical Note, Applied Research Associates, Arlington, VA.

Stricklin D and Reeves G, 2015. Selection of a dose response relationship for radiation lethality with treatment for implementation in HENRE. ARA Technical Note, ARA/HS-TN-15007-B. Applied Research Associates, Arlington, VA.

Summers, C., Rankin, S.M., Condliffe A.M., Singh, N., Peters, A.M., and Chilvers, E.R., 2010. "Neutrophil Kinetics in Health and Disease," Trends in Immunology, 31(8):318-24.

Tintinalli, J.E., 2011. Emergency Medicine: A Comprehensive Study Guide. McGraw-Hill, New York, NY.

Trier, J. S., and Browning, T. H., 1966. "Morphologic response of the mucosa of human small intestine to x-ray exposure." Journal of Clinical Investigation, 45(2), 194-204.

Ullrich, R.L., and Casarett, G.W., 1977. "Interrelationship between the Early Inflammatory Response and Subsequent Fibrosis after Radiation Exposure," Radiation Research, 72(1):107-121.

Umar, S., 2010. "Intestinal Stem Cells," Current Gastroenterology Reports, 12(5):340-348.

Valentin, J., 2002. "Basic Anatomical and Physiological Data for Use in Radiological Protection: Reference Values," ICRP Publication 89, Annals of ICRP, 32(3-4):1-277.

Vanderschueren S, De Weerdt A, Malbrain M, Vankersschaever D, Frans E, Wilmer A, et al., 2000. "Thrombocytopenia and prognosis in intensive care." Critical Care Medicine, 28(6):1871-1876.

Velkey, M., 2009. Gastrointestinal and Liver, Winter 2009. Open.Michigan, Regents of the University of Michigan, Ann Arbor, MI. http://open.umich.edu/education/med/m1/giliver/winter2009. Accessed on February 17th, 2015.

Volenec, F.J., Wood, G.W., Mani, M.M., Robinson, D.W., and Humphrey, L.J., 1979. "Mononuclear Cell Analysis of Peripheral Blood from Burn Patients," The Journal of Trauma, 19(2):86-93.

Waters, C.M., Taylor, J.M., Molteni, A., and Ward, W.F., 1996. "Dose-response Effects of Radiation on the Permeability of Endothelial Cells in Culture," Radiation Research, 146(3):321-328.

Wentz, J., Oldson, D., and Stricklin, D., 2014. Mathematical Models of Human Hematopoiesis Following Acute Radiation Exposure. DTRA-TR-14-031, Defense Threat Reduction Agency, Fort Belvoir, VA.

Wentz J., Stricklin D., Millage M., 2015a. Updates to Blast Injury Criteria Models for Nuclear Casualty Estimation. DTRA-TR-15-023. Defense Threat Reduction Agency, Fort Belvoir, VA. 
Wentz, J., 2015b. Implementation of the Small Intestine Model Developed by Smirnova 2010 in R. ARA/HS-TN-15-005-A, Applied Research Associates, Inc., Arlington, VA.

Wentz, J., 2015c. Parameterization of Small Intestine Model of Radiation Injury in Mice and Humans. ARA/HS-TN-15-006-A, Applied Research Associates, Inc., Arlington, VA.

Wentz, J., Oldson, D., and Stricklin, D., 2015d. Models of Hematopoietic Dynamics Following Burn for Use in Combined Injury Simulations. DTRA-TR-15-024, Defense Threat Reduction Agency, Fort Belvoir, VA.

Wentz, J.M., Vainstein, V., Oldson, D., Gluzman-Poltorak, Z., Basile, L.A., Stricklin, D., 2015e. "Mathematical Model of Radiation Effects on Thrombopoiesis in Rhesus Macaques and Humans," Journal of Theoretical Biology, 29(383):44-60.

Wiernik, G., Shorter, R.G., and Creamer, B., 1962. “The Arrest of Intestinal Epithelial 'Turnover' by the Use of X-irradiation," Gut, 3:26-31.

Williams, C., 2009. "Successful Assessment and Management of Burn Injuries," Nursing Standard, 23(32):53-62.

Willoughby, D.A., 1960. "Pharmacological Aspects of the Vascular Permeability Changes in the Rat's Intestine Following Abdominal Radiation," The British Journal of Radiology, 33:515-519.

Withers, H.R., 1971. "Regeneration of Intestinal Mucosa after Irradiation," Cancer, 28:75-81.

Wright, N.A., and Irwin, M., 1982. "The Kinetics of Villus ell Populations in the Mouse Small Intestine. I. Normal Villi: the Steady State Requirement," Cell and Tissue Kinetics, 15(6):595-609.

Zuckerman, S., Burns, B. D., and Black, P. M., 1944. The Wounding Power of Debris. Report R.C. 423, Ministry of Home Security, Oxford, England. 


\section{Section 7.}

\section{Abbreviations, Acronyms and Symbols}

$\begin{array}{ll}\text { AMedP } & \text { Army Medical Publication } \\ \text { ARA } & \text { Applied Research Associates, Inc. } \\ \text { ARS } & \text { Acute radiation syndrome } \\ \text { CI } & \text { Combined injury } \\ \text { CIn } & \text { Combat Ineffectiveness } \\ \text { CHRNEM } & \text { Consolidated Human Response Nuclear Effects Model } \\ D & \text { Dose } \\ D_{i}^{0} & \text { Dose that results in one hit per target } \\ \text { d } & \text { days } \\ \text { DoA } & \text { Department of the Army } \\ \text { DHS } & \text { Department of Homeland Security } \\ \text { DoD } & \text { Department of Defense } \\ \text { DTRA } & \text { Defense Threat Reduction Agency } \\ \text { EM-1 } & \text { Effects Manual - 1 } \\ \text { FI } & \text { Fatal injury } \\ \text { FIA } & \text { Free-in-air } \\ G & \text { Perturbation of a specific parameter } \\ \text { GI } & \text { Gastrointestinal } \\ \text { Gy } & \text { Gray } \\ \text { HENRE } & \text { Health Effects from Nuclear and Radiological Environments } \\ \text { HPAC } & \text { Hazard Prediction and Assessment Capability } \\ \text { hr } & \text { hours } \\ \text { HSC } & \text { Hematopoietic stem cells } \\ \text { IV } & \text { intravenous } \\ \text { LA } & \text { Lethal area of burn } \\ \text { LFMER } & \text { Lovelace Foundation for Medical Education and Research } \\ \text { MI } & \text { Moderate injury } \\ \text { min } & \text { minutes } \\ \text { MKs } & \text { Megakaryocytes } \\ \text { MVES } & \text { Microvascular Exchange System } \\ \text { NATO } & \text { North Atlantic Treaty Organization } \\ n_{i} & \text { Average number of hits required to damage a cell in compartment } \\ \text { NETs } & \text { Neutrophil extracellular traps } \\ & \end{array}$




$\begin{array}{ll}\text { NK } & \text { Natural killer } \\ \text { PRCC } & \text { Personnel Risk and Casualty Criteria } \\ r & \text { Relaxation coefficient } \\ \text { RIPD } & \text { Radiation-Induced Performance Decrement } \\ \mathrm{s} & \text { seconds } \\ \mathrm{S} & \text { Surviving fraction of cells } \\ \text { SI } & \text { Severe injury } \\ \text { SIM } & \text { Small intestines model } \\ \text { SMEs } & \text { Subject matter experts } \\ \text { SNS } & \text { Strategic National Stockpile } \\ t & \text { Time elapsed after injury } \\ \text { TPO } & \text { Thrombopoietin } \\ \text { WMD } & \text { Weapons of mass destruction } \\ \text { UMI } & \text { User's Managed Inventory } \\ \% \text { TBSA } & \text { Percent of total body surface area }\end{array}$

